NBER WORKING PAPER SERIES

ADDRESSING CLIMATE CHANGE THROUGH PRICE AND NON-PRICE INTERVENTIONS

Joseph E. Stiglitz

Working Paper 25939

http://www.nber.org/papers/w25939

\author{
NATIONAL BUREAU OF ECONOMIC RESEARCH \\ 1050 Massachusetts Avenue \\ Cambridge, MA 02138 \\ June 2019
}

I am deeply indebted to Linus Mattauch, Cameron Hepburn, and Naman Garg, and two very helpful anonymous referees for their detailed and helpful comments. I am also indebted to Nick Stern for long conversations about the subjects covered here, and the members of the High-Level Commission on Carbon Prices for their insights and debates over the issues discussed here. I am also indebted to Andrea Gurwitt for her editorial assistance. Financial support was provided by INET. The views expressed herein are those of the author and do not necessarily reflect the views of the National Bureau of Economic Research.

NBER working papers are circulated for discussion and comment purposes. They have not been peer-reviewed or been subject to the review by the NBER Board of Directors that accompanies official NBER publications.

(C) 2019 by Joseph E. Stiglitz. All rights reserved. Short sections of text, not to exceed two paragraphs, may be quoted without explicit permission provided that full credit, including () notice, is given to the source. 
Addressing Climate Change through Price and Non-Price Interventions

Joseph E. Stiglitz

NBER Working Paper No. 25939

June 2019

JEL No. A1,H23,K32,Q52,Q54,Q55

\begin{abstract}
$\underline{\text { ABSTRACT }}$
Recognizing the importance of the second-best nature of economies, the Stern-Stiglitz report on carbon pricing departed from the recommendation of a single carbon price for all uses at all places and times. This paper provides some of the analytics behind these recommendations. First, I analyze the circumstances in which distributional concerns make desirable a tax or regulation inducing significant reductions in carbon usage in a carbon-intensive sector for which consumers are disproportionately rich. Such policies allow lower carbon prices elsewhere without exceeding carbon emission targets. The cost of the resulting production inefficiency may, under the identified circumstances, be less than the distributional benefits. The paper considers the circumstances in which such differential policies may be best implemented through regulation vs. differential pricing, as well as differential effects on political economy and norm setting. Second, I consider the effect of carbon price trajectories on induced innovation, providing general conditions under which the optimal carbon path should, at least eventually, be falling over time. Finally, I revisit the price-versus-quantity debate and highlight important aspects of the dynamic nature of the problem.
\end{abstract}

Joseph E. Stiglitz

Uris Hall, Columbia University

3022 Broadway, Room 212

New York, NY 10027

and NBER

jes322@columbia.edu 


\title{
Addressing Climate Change through Price and Non-Price Interventions
}

\author{
Joseph E. Stiglitz ${ }^{1}$
}

\section{Introduction}

Economists have had a long predilection for price interventions to correct market failures such as those arising from the presence of externalities. The reason is simple: market efficiency requires equating private and social returns, the presence of an externality means that there is a gap between the two, and a price intervention can close the gap, restoring efficiency. In the context of climate change, the prescription is to price carbon, and since what matters is the atmospheric concentration of greenhouse gases, and since the rate of decay of, say, carbon dioxide is so slow, the price of carbon should be (approximately) the same for all uses, at all places, and at all dates. (IPCC 2013; Stiglitz, 2013; Millar et al., 2016;; Dietz and Venmans, 2017; van der Ploeg, 2018). ${ }^{2}$

If only things were so simple. There are several fundamental departures from this simplistic world, all speaking to the point that we are always in a second- or third-best world, and in such a world, naively moving the economy seemingly closer to first best may entail a lowering of social welfare. ${ }^{3}$

The Stern-Stiglitz High-Level Commission on Carbon Prices (2017), while recognizing that “A well-designed carbon price is an indispensable part of a strategy for reducing emissions in an efficient way," departed from the "single price of carbon in all place, dates, and uses," calling

\footnotetext{
${ }^{1}$ University Professor, Columbia University. I am deeply indebted to Linus Mattauch, Cameron Hepburn, and Naman Garg, and two very helpful anonymous referees for their detailed and helpful comments. I am also indebted to Nick Stern for long conversations about the subjects covered here, and the members of the High-Level Commission on Carbon Prices for their insights and debates over the issues discussed here. I am also indebted to Andrea Gurwitt for her editorial assistance. Financial support was provided by INET.

${ }^{2}$ The economic argument for a single price is straightforward: Climate change is a result of the increase in the atmospheric concentrations of carbon dioxide and other greenhouse gases. Assume, for instance, that there were a precise carbon budget - no climate change so long as carbon concentration was below a critical threshold, and unacceptable change over that level. Because of the long duration that any $\mathrm{CO}_{2}$ molecule entering the atmosphere remains there, we don't care when the molecules enter the atmosphere. There is thus a shadow price associated with molecules entering the atmosphere-and this is the carbon price, the same at all places and times.

Other greenhouse gases obviously also play a role in climate change, and because they are (relatively) shortlived, it is not quite accurate to focus only on the long run.

${ }^{3}$ See Lipsey and Lancaster (1956) for a general theory of second best.
} 
for "explicit price trajectories." The Commission, in formulating optimal strategies for meeting the Paris and Copenhagen goals, also did not rely exclusively on carbon pricing, suggesting that such pricing "may need to be complemented by other well-designed policies tackling various market and government failures, as well as other imperfections." It observed that, "Adopting other cost-effective policies can mean that a given emission reduction may be induced with lower carbon prices than if those policies were absent." All of these considerations represent marked departures from the standard first-best model alluded to in the first paragraph of this paper. While these ideas received the support of all the members of the Commission, the Commission in its report did not provide analytic justifications for these departures from the conventional wisdom. Implicitly, the report seems to suggest different shadow prices of carbon across time, over space, and with different uses, and that these shadow prices would themselves be contingent on information as it was revealed. ${ }^{4}$

The intent of this paper is not to provide a general alternative analytic framework, but through a series of simple, partial equilibrium models, to enhance our intuition for the Stern-Stiglitz recommendations, and to provide a better sense of the circumstances under which a deviation from the "single price" might be desirable, and the form that such deviations might best take. We focus in particular on distribution and induced innovation, and the appropriate responses to uncertainties about developments in technology and our knowledge of climate change, including its economic and social impacts.

We draw on the extensive public finance literature that has addressed analogous questions. Unfortunately, many of the complicated and subtle insights from that literature have not been fully brought into discussions related to climate change. While earlier literature on corrective taxation in a second-best world with optimal commodity taxation (Sandmo, 1975) there were no pure profits and no restrictions on commodity taxes-suggested that a standard Pigouvian analysis in which simple taxes can address externalities would apply, more recent

\footnotetext{
${ }^{4}$ Even a single carbon price "at all places, at all dates, and in all uses" will be state contingent, i.e. will change with changes in information about technology and damage, so that in practice, the carbon price will change over time. ${ }^{5}$ Baumol and Oates (1971) argued for the desirability of using Pigouvian taxation even when there was uncertainty about the appropriate level of emission reductions.
} 
work has questioned these results. One essential question relates to the circumstances in which the Diamond-Mirrlees efficiency conditions apply (Diamond and Mirrlees, 1971). When it does, then a Pigouvian corrective tax ensures production efficiency, and optimal consumption (including optimal wage) taxes can be used to raise the requisite revenue in a way that maximizes social welfare (or alternatively, do so in a way that is Pareto efficient. ${ }^{6}$ ) Unfortunately, it turns out that the conditions under which the Diamond-Mirrlees efficiency hold are very restrictive, requiring, for instance, a wide range of rent, profits, and differential product and wage taxes (Dasgupta and Stiglitz, 1971, 1972). And even more so when individuals differ in their abilities and relative wages are endogenous and offsetting differential wage taxes cannot be levied or when they differ in their ownership of other assets the returns to which could not be fully differentially taxed (Stiglitz, 1998a, 2018b). Thus, with restrictive taxation, a tax on carbon could lead to a change in the distribution of income or well-being, either because of direct price effects or because of indirect general equilibrium effects on relative wages and prices; and the government may not have at its disposal instruments to undo these distributive effects. In these cases, Pigouvian corrective taxation does not suffice to "undo" the externality in ways which maximize societal welfare. In short, in the second-best world in which we live, there is no presumption that a carbon tax alone can suffice to address optimally the problem of climate change. To the contrary, there is a presumption that additional interventions can increase societal welfare. $^{7}$

\footnotetext{
${ }^{6}$ For a general analysis extending the standard theory of optimal taxation to the theory of Pareto efficient taxation, see Stiglitz (1987).

${ }^{7}$ The mathematics establishing these results is straightforward. The usual Lagrangean associated with maximizing social welfare (and Pareto optimality, where the well-being of one group is maximized subject to the levels attained by other groups) incorporates the limitations on government redistribution, e.g. by embedding selfselection constraints and limiting the set of taxes/interventions. It turns out that with specific utility functions, where, for instance, leisure is separable from goods and where the effects of climate change are separable from goods and leisure, and if the government is allowed to impose unrestricted non-linear income and commodity taxes, then the standard efficiency results can be restored (Kaplow, 1996, 2006, building on Atkinson and Stiglitz, 1976). But even with strong separability conditions, if the government were restricted in its income tax, say to a linear income tax, then public policy once again has to take into account distributive effects (Stiglitz, 2009).

The work of Goulder, Hafstead, and William (2016) can perhaps best be looked at in this way. They provide a special model in which they show the desirability of using a clean energy standard over simply using a price: "On the other hand, lower electricity prices have a virtue associated with tax interactions. Because it gives rise to a less pronounced increase in electricity prices, the [clean energy standard (CES)] leads to smaller distortions caused by the tax system. Our models indicate that this offsetting benefit makes the CES nearly as cost-effective as-and in some cases more cost-effective than-the equivalent emissions price policy" (p.188). Our analysis is very much in
} 
Earlier results showing that when information is imperfect and/or asymmetric and risk markets incomplete - that is always - markets are not (constrained) Pareto efficient imply, of course, that climate change is never the only "market failure." 8 These microeconomic externalities imply there are likely to be significant macroeconomic externalities (Jeane and Korinek, 2010) that government policy will need to take into account. While these, too, may sometimes be effectively addressed through price interventions, the relevant price interventions will differ from sector to sector, depending on the nature of these macroeconomic externalities and spillovers. Moreover, private decisions are also affected by publicly provided infrastructure. While prices may help guide these decisions, inevitably market imperfections, such as those associated with geography, loom large, and limit the guidance that can be provided by carbon prices alone. And government itself seldom relies on pricing alone (or even shadow prices) in making its resource allocations. ${ }^{9}$

It is this and similar insights, all of which can be framed as second or third best deviations from the "standard model," that informed our thinking. If the standard economists' arguments were correct, and if (as is conventionally assumed) citizens are rational, it would appear that there should be strong support for a carbon tax, accompanied perhaps by some measures to ensure that those who might lose from a carbon tax are made whole. But so far, few countries have

their spirit, though they do not point out clearly what departure from the Diamond-Mirrlees model justifies a departure from using a single price intervention. In the analysis below, as we'll see, the departure relates to costly redistributions, which seem not to play the central role in their model.

While this paper focuses on costly redistributions, other restrictions in the set of admissible taxes also give rise to the desirability of going beyond just a carbon tax, for instance, restrictions on the imposition of different tax rates on different products and restrictions on the imposition of taxes on rents. When, for instance, there are rents, a higher carbon tax may be viewed as an indirect way of taxing rents in some sectors.

The difference between Ramsey's analysis of commodity taxation-where taxes were related to the elasticity of supply as well as demand-and that of Diamond and Mirrlees - where only demand is relevant-arises from the absence of rents in the latter model or the complete taxation away of those rents. See Dasgupta and Stiglitz (1971).

Cross-country redistributive issues are more complex, and more difficult to resolve, than those addressed here, and this provides an even more compelling case for a deviation from a global single carbon price. See Stiglitz (2017).

${ }^{8}$ See Greenwald and Stiglitz (1986) and Geanakoplos and Polemarcharkis (1986). The term "constrained Pareto optimality" simply refers to the fact that, even taking into account the costs of obtaining information and creating markets, the equilibrium is not Pareto efficient.

${ }^{9}$ Stiglitz (2018b) explains why, even if it were guided by shadow prices, government would not necessarily want to use the same shadow prices for all projects, in all periods, and in all locations, and would not want to use the same prices used by markets. 
enacted significant carbon taxes, let alone relied on them to curb the use of fossil fuels, and there remains significant opposition from various quarters. In one sense, this paper is an enquiry into whether there might exist a rationale for such opposition, and if so, are there reforms in the design of the carbon tax (perhaps along the lines suggested by the Stern-Stiglitz Report) that might result in a broader consensus behind it.

Beyond the introduction and the conclusion, this paper is divided into four sections. In the first, I lay out some of the important, but not always transparent, assumptions that shape public policy. In the second, I focus more narrowly on designing carbon policy when distributional considerations are important, and there are not first best, or often even second best, mechanisms for undoing the distributive consequences of carbon pricing. In the third, I focus on the interactions between pricing trajectories and innovation, addressing the question of whether it might be desirable to begin with a high carbon price which would subsequently be reduced. In the fourth section, I have a few remarks about an old puzzle-the merits of using prices vs. quantities -in the context of climate change.

\section{The core assumptions}

This paper is, in many ways, an exploration of optimal policy in contexts in which there are multiple market failures and public policy constraints, not just a single market failure- excessive emissions of carbon that could be corrected by a single intervention, imposing a carbon price. 10 It may be useful, in this introductory section, to lay out the range of deviations from the standard first best model and the constraints on government that we will explore in subsequent sections.

The standard simple model of optimal environmental intervention has a well-defined damage function, a well-defined damage abatement (emissions reduction) function, a representative consumer, and costless adjustment, and the only market failure is the absence of a carbon price. In this context, it is obvious that direct regulation (specifying the quantity of allowable

\footnotetext{
10 As we have noted in the next section, we focus on limitations on the ability to redistribute income, limitations which, in turn, may be explicable in terms of imperfections of information. See Mirrlees (1971) and Stiglitz (1987b). In section 4, we focus on inherent market failures in the innovation process.
} 
emissions) and price regulation (specifying a fine for emissions) are equivalent. Much of the "folk" policy literature assumes that the government may not know precisely the abatement function or even the damage function at the time the policy is imposed. If, of course, the government knows precisely the marginal damage cost, then imposing a fine equal to the marginal damage cost achieves the first best outcome. But if, as in Weitzman (1974), the damage function is itself unknown ${ }^{11}$, then ex ante, we don't know what the optimal fine (price) should be. Weitzman's early analysis made it clear, at least as a matter of principle, that the economists' presumption in favor of the use of price interventions was more limited than had previously been thought. ${ }^{12}$

This paper explores a set of complementary reasons for policy to go beyond a carbon tax in support of the conclusions of the Stern-Stiglitz Commission, some of which go beyond the considerations that have preoccupied optimal tax-and-expenditure theory.

2.1. Welfare criteria. Much of this paper focuses on the observation that carbon taxes have distributive implications. In particular, it may be (if carbon consumption increases less than in proportion to income), and be perceived to be, regressive. ${ }^{13}$ Levinson (2018) argues that for the US, the rich consume more energy but not proportionately so, so that a carbon tax is regressive. More broadly, it can have large adverse distributive consequences which cannot easily be undone. ${ }^{14}$ This was illustrated by the refrain of France's yellow vest protestors in response to the proposal for an increase in gasoline taxes, viewed as part of

\footnotetext{
${ }^{11}$ Or if there is uncertainty about the abatement function and the damage function is upward-sloping.

12 In a sense, Weitzman's work could be set in the context of the extensive work on optimal policy, and especially optimal taxation, with asymmetries of information between the government and agents, where it had been shown that it was optimal to have non-linear interventions, i.e. neither relying on price or quantity interventions, if such non-linear interventions are implementable. The formal similarities between the various screening/signaling/optimal tax models are, by now, well-recognized. See, e.g. Mirrlees $(1971,1975)$ and Atkinson and Stiglitz (1976, 1980).

${ }^{13}$ Even if a carbon tax is progressive, it may be less progressive than other tax instruments, so that shifting towards a carbon tax can reduce the progressivity of the tax system. Of course, as we discuss below, there are other changes to policy that can offset these effects, but whether these offsetting measures will be undertaken and sustained is a different matter, which we also discuss below.

${ }^{14}$ By adverse distribution effects, we simply mean redistributions that lower the level of social welfare under an inequality averse social welfare function, e.g. distributive effects against the poor.
} 
the broader agenda of creating a carbon price in France. "The government talks about the end of the world. We are worried about the end of the month." ${ }^{15}$ (Of course, it didn't help that the government had earlier lowered taxes on the wealthiest French citizens.)

At least for some important aspects of energy consumption-in the home and for public transportation-prices charged the poor do not have to increase in tandem with the price of carbon. There can be non-linear electricity tariffs that undo the distributive effects of the carbon tax for the poor, and public transportation, especially for the poor, can be subsidized. More generally, there are combinations of interventions that may reduce carbon consumption and still be progressive

In addition to the standard vertical inequities (between the rich and the poor), we also consider horizontal inequities (impacts of a tax on individuals, say, with the same income, who differ in their consumption preferences). Such differences provide a critique of proposals to rebate the carbon $\operatorname{tax}^{16}$. While on average, a uniform lump sum payment may more than compensate low income individuals for increased energy costs - the evidence, as we have already noted, is that carbon consumption on average increases with income-there are sub-groups for whom that may not be true. A more distributively sensitive but less efficient policy-a carbon tax exempting fuel (which already has a high implicit carbon tax)-might increase social welfare and might not have run into such opposition. ${ }^{17}$

\footnotetext{
${ }^{15}$ Interestingly, transportation may be the one sector in which energy/carbon usage increases more than in proportion to income, partly because many poor do not own cars. See Grainger and Kolstad (2010) for the US. More generally, see Flues and Thomas (2015) and Sterner (2012). The yellow-vests protests seems to have reflected concerns of a particular subgroup that face high fuel costs. Because of where low income housing is located in relation to work opportunities, the working poor often have to travel long distances.

${ }^{16}$ Such a proposal received the support of a broad coalition of American economists in a letter published in the Wall Street Journal on January 19, 2019. Other critiques are based on the arguments provided in later sections of this paper, as well as the inefficiencies of providing lump sum redistributions and subsequently having to impose distortionary taxes to raise revenues, including those required for green infrastructure. The major argument put forward for such proposals is based on political economy, the ability to garner sufficient political support for a carbon tax. We comment on these political economy arguments below.

${ }^{17}$ In the discussion below, we will explain why the government may not able to offset these distributional impacts.
} 
Governments are often adverse to policies that introduce large differences among individuals who previously seemed similarly situated, even if the differences are related to the extent to which they generate negative societal externalities ${ }^{18}$. This is especially true if the government is sensitive to loss aversion ${ }^{19}$ - the fact that those who lose from the high carbon tax lose more, or perceive those losses more intensely, than those who gain from the restructured tax structure (e.g. from lower taxes on labor and capital).

The significance of these distribution effects will depend, of course, on the nature of the economy and the set of instruments available to government. The costs of undoing any adverse distributive consequences is affected also by the diversity of the population. Distributive consequences will be larger in a society in which there are greater disparities in income and greater societal heterogeneity. The former is a standard argument in the theory of optimal taxation, but the latter has not been given sufficient attention, partly because much of the literature, beginning with Mirrlees (1971), focused on vertical inequalities in models where all individuals of a given income were identical. An implication is that it might be desirable to have more reliance on regulations and restraints in an economy with a high level of inequality and diversity, like the US, than in a society with greater equality and less diversity.

Still a third concern is risk. Individuals are risk averse, and cannot obtain insurance against many of the risks that they face-including the uncertainties posed by policy itself. In a world in which individuals may not be sure about the full distributive consequences of a carbon tax, risk aversion will mean that a carbon tax lowers their ex ante expected utility. Risk averse individuals may believe that a carbon tax (even when accompanied by a lump-sum

\footnotetext{
${ }^{18}$ And even if similar changes in well-being could have resulted from changes in market prices. The implication for the cost of energy of the Stern-Stiglitz recommended price of carbon is far smaller than variations in the prices of energy that have often occurred over the past 40 years. (See, for instance, Stiglitz 2018c).

${ }^{19}$ See, e.g. Tversky and Kahneman 1991. As we note below, individuals may not be fully aware of their levels of carbon consumption, and therefore of the impact of say a carbon tax. Loss aversion is defined relative to their current level of utility.

Similar results may hold in a standard utilitarian analysis with concave utility functions, where individuals differ in their preferences, even when the carbon tax is uniformly fully rebated. For non-negligible taxes, the increase in utility of the gainers (low carbon consumers) may be less than the loss in utility of the losers (high carbon consumers). This is even more so, as we note below, in a standard ex ante utilitarian analysis where individuals are uncertain about the consequences of the carbon tax, even if they have rational expectations concerning average impacts.
} 
redistribution) might make them worse off, simply because they are uncertain about the general equilibrium effects. ${ }^{20}$

A fourth concern (taken up briefly in section 5) combines risk and the absence of a full set of insurance markets and fully state contingent policies and a particular aspect of distributionintergenerational equity. Alternative policies have implications for intergenerational distribution, including that of risk bearing, the consequences of which are not fully offset by intergenerational transfers. ${ }^{21}$

There is a final set of modifications to the simplistic welfare framework that we take into account: adjustment is costly, both financially and psychically, and it is the latter that raises the most problematic issues.

Moreover, advances in behavioral economics have detailed the many ways in which individuals differ from the homo oeconemus of standard theory, both in limited cognitive capacities and in the endogeneity of preferences, which to a large extent are culturally determined. ${ }^{22}$ Policies

\footnotetext{
${ }^{20}$ These individuals will, of course, oppose the tax, unless there is some credible way to compensate them. There is clearly a close relationship between these risk effects and the horizontal inequities discussed in the previous paragraphs, where particular individuals may believe that a carbon tax accompanied by a uniform lump sum distribution may make them worse off also because they believe that their (general equilibrium) carbon consumption might be greater than the average per capita and/or they believe that their costs of adjustment are significant. Imperfections in competition may also result in adverse distribution effects, with goods prices going up more than proportionately to costs of production. The imposition of a carbon tax may provide an opportunity for those with market power to take advantage of them. There is ample evidence that firms often increase prices following an increase in taxes in ways that are markedly different from what one would have expected in a fully competitive equilibrium. Uncertainty about the degree of market power (and there is again ample evidence of such uncertainty, especially in the midst of on-going increases in market power) will lead to uncertainty about the effects of a carbon tax.

${ }^{21}$ Limitations in such intergenerational transfers is one of the reasons that the rate of discount to be used in social cost benefit analysis may differ from the pure rate of discounting of future generations (plus an adjustment for the decline in marginal utility as a result of technological change). See, e.g. Stiglitz 1982. (Other reasons have to do with other market imperfections, e.g. limitations in the ability to costlessly transfer money from the private sector to the public. See Stiglitz 2018b.)

${ }^{22}$ This has been called by Hoff and Stiglitz (2016) the second strand of behavioral economics. The original work in behavioral economics, based on insights from psychology, focused on cognitive limitations, analyzing how these often led to decisions that seemed inconsistent with individuals' deep preferences. This second strand, by contrast, draws on insights from social psychology and sociology, and is centered on the determination of these deep preferences and societal norms. There is a growing literature on endogenous preferences and how preferences and norms are shaped. See, e.g., Bowles $(1998,2016)$.

An often cited example is Israeli day care centers: charging parents for picking up their children late from a daycare center actually exacerbated the problem of late pickups. Previously, it had been a "norm" to pick up a child on time, and parents struggled to conform to the norm. But a charge made a late pickup into an ordinary
} 
predicated on analyses of rational agents with fixed preferences often go astray, simply because the underlying predicate that agents are rational with fixed preferences is so off the mark. Public policies aimed at increasing savings making use of insights from behavioral economics seem far more efficacious than those based on the conventional model of individuals maximizing the standard intertemporal utility function. And this may be particularly important when it comes to the establishment of norms when individually rational behavior is so out of tune with societal well-being.

One important insight of behavioral economics already noted is that individuals are "loss averse." This means that the societal consequences of a policy that symmetrically imposed losses on some individuals and gains to others would lower social welfare: the losses of the losers would be more salient than the gains of the winners. Greater salience can easily translate into greater political activism. ${ }^{23}$

The introduction of behavioral economics into our analysis, though, presents a challenge which this paper cannot resolve: We know less about the determinants either of preferences and norms or of deviations from full rationality than we would like. While even if we can't provide adequate answer to the relative merits of prices and regulations in changing preferences and norms, it is important to raise the issue: in the end, this question may be of first order importance.

2.2. Innovation. A standard result in modern welfare economics is that market economies are essentially never efficient when it comes to the pace and direction of innovation. (Stiglitz and Greenwald, 2014). Knowledge is a quasi-public good, and there are significant spillovers from innovation. Government policies can affect the direction of innovation, and

commodity, with parents evaluating the costs and benefits (Gneezy and Rustichini, 2000). For a more recent survey, see Gneezy et al 2011

Endogeneity of preferences poses difficult problems in welfare economics (see, e.g. Gintis, 1974), but, as we shall see, can play an important role in addressing climate change. In the context of climate change, see also Mattauch and Hepburn, 2016.

${ }^{23}$ There is some controversy about whether it is appropriate to use loss aversion to analyze welfare implications of alternative policies. Kahneman, Wakker and Sarin (1997) emphasize the difference between "Decision Utility" and "Experienced Utility." While loss aversion may correctly capture the weights humans put on decisions, it may not capture "Experienced Utility" well. 
not just through its role in providing direct support, especially for basic research. It can, for instance, do so through prices and regulations. A long-established theory of induced innovation provides an intellectual framework guiding us in understanding how that happens and the merits of alternative policies.

These issues interact, of course, with those discussed earlier: innovation can have significant distributive effects, and changes in norms, preferences, and capabilities can both help shape the direction of innovation and affect the social consequences.

\subsection{Political economy. Economists often refer vaguely to "political constraints": a}

particular policy (such as a carbon tax) would be first best, but because of ill-defined political constraints, there is a need for a second best policy. My experience in politics has left me with an uncertain feeling about such constraints: sometimes, they seem real and binding until they suddenly disappear; the art of politics entails persuading others that something that might seem economically and politically infeasible in fact is feasible. ${ }^{24}$ There are two real aspects of political decision-making that cannot not be ignored. The first is time consistency. Time consistency problems arise whenever there are long term decisions, and as such are particularly pertinent to innovation: The government has an incentive to persuade the private sector to develop low carbon technologies, but once developed, the marginal social cost of carbon might decrease, thus allowing it to charge a low carbon price.

But at a low carbon price, the development of the new technology would not have made sense. Of course, if private agents view governments as having a time consistency problem, the

\footnotetext{
${ }^{24}$ Sometimes, the political constraints are another way of saying, "if we could only ignore issues of distribution." But of course we can't. Distributive consequences are of first order importance.

Earlier, we referred to the distributive issues raised by horizontal inequities. Government policies creating horizontal inequities are sometimes viewed as unacceptable-even though when such disparities are created by the market they seem acceptable. Thus, it may be viewed as "unfair" and therefore unacceptable for government to impose a carbon tax that hurts those who have to drive to work, even though an increase in the oil price that would have the identical effect is accepted. The reason may be the seeming anonymity of market forces while it is often difficult to evaluate the true motives and rationale behind government policies. In contrast, it is possible, and perhaps even plausible, that non-drivers might get together in a political process to advantage themselves at the expense of drivers.
} 
initially announced price or regulatory path will not be viewed as credible, and therefore will not have the desired effect. (Helm et al 2003).

Here's where the second, and often neglected, aspect of political economy enters: policies today can affect the coalitions that form and agents' behavior (investments) in such a way that their future interests are changed; and this may alter the political support for policies in the future. Indeed, this was part of the rationale for the Paris strategy: if enough firms believed that there was enough global commitment to climate change that there would be a high carbon price (implicit or explicit) going forward, they would have an incentive to make green investments; and to ensure that they were advantaged over firms that didn't make such investments and to ensure that they obtained the desired returns on those investments, they would then politically support, in coalition with other like-minded agents, a high carbon price. ${ }^{25}$

Time consistency, and questions about whether there is a political resolution, enter repeatedly in policy analysis. In multiple contexts, a policy is described which grows the economic pie, so everyone could be made better off. But that's far different from a policy that will make everyone better off. Even if government engages in compensatory actions today so that everyone is better off now, it may be difficult for the government to commit itself to sustaining those compensatory policies. ${ }^{26}$ Moving beyond the "single price in all uses, at all dates, and at

\footnotetext{
${ }^{25}$ There is a fixed cost associated with forming coalitions; and the formation of such coalitions is like a public good. Once established, the coalitions can be self-sustaining, and result in the continuation of the policies. For an earlier discussion, see Stiglitz (1998b).

More generally, there can be a multiplicity of such political/economic equilibria. See Hoff and Stiglitz (2004, 2007), who study a transition from a "lawless" state to one governed by a rule of law in the context of the transition from Communism to a market economy. There are obvious analytic parallels between that transition and the transition from a high-carbon (where there is a dearth of rules governing carbon emissions) to a lowcarbon economy.

At least partial time consistency can be obtained even in a contestable democracy, where future governments may not fully share preferences (values) and the current government cannot fully commit future governments to any course of action. Investments both in the private and public sectors are, for instance, reversible but only partially so, especially in the short run. Even reversible policies (e.g. a change in tax rates) can lead to only partially reversible actions (i.e. long-term investments), and these can affect both future patterns of voting and behavior. See Korinek and Stiglitz $(2008,2009)$ for a discussion of the general theory in the context of a game theoretic model with two parties and an application.

${ }^{26}$ For a discussion in the context of globalization and technical change, see Korinek and Stiglitz, 2019.
} 
all places" increases the set of feasible policies, and thus the prospect of finding a policy that avoids politically unacceptable redistributive effects in a time-consistent way.

\section{Distribution}

A central reason, we have argued, for going beyond a single carbon price relates to distribution. Changes in prices, regulations, and government investments each can have large redistributive effects. There may be large costs associated with undoing the distributional effects, and, given limitations in information available to government, the adverse effects on distribution may not be able to be undone and, in any case, can never be undone perfectly and costlessly. The question on which we focus in this section is whether there may be regulations and/or more complex pricing policies that achieve similar environmental goals as a simple carbon tax with fewer adverse distributive consequences. Though regulations might not be first best, i.e. would not be chosen if redistributions were costless, once the costs of redistributions are taken into account, they are socially desirable. ${ }^{27}$ Throughout the analysis of this section, we assume there is a carbon tax. We show, however, that under certain circumstances, regulations ${ }^{28}$ may reduce the general level of the carbon tax required to achieve a given reduction in carbon emissions, reduce the magnitude of the resulting adverse distribution, and as a consequence, increase societal welfare.

\subsection{A Simple Model}

We begin by ignoring uncertainty and dynamics, focusing simply on the question of the best way to achieve, for example, a given reduction in carbon. ${ }^{29}$ Figure $1 \mathrm{~A}$ illustrates the carbon tax that achieves the given level of carbon emissions, with the level of carbon emissions falling as the carbon price increases. Assume there is some important sector $\mathrm{j}$, which is very carbon intensive and such that for that sector, a switch to a low carbon-intensive production

\footnotetext{
${ }^{27}$ We emphasize that this is a theoretical exercise. We are not evaluating the relative merits of any particular regulatory measure designed to supplement a carbon tax.

${ }^{28}$ or differential carbon taxes in different usages

${ }^{29}$ As we have emphasized, the amount of reduction that is desirable is itself an endogenous variable in a fuller analysis.
} 
technology only occurs at a very high carbon price. ${ }^{30}$ We identify a switching price, $\mathrm{p}^{*}$, at which it switches to a low carbon technology. The switching price $\mathrm{p}^{*}$ determines the carbon price required to achieve emission levels of $E^{*}$; at a price below $\mathrm{p}^{*}$, the level of carbon emissions exceeds the desired level.

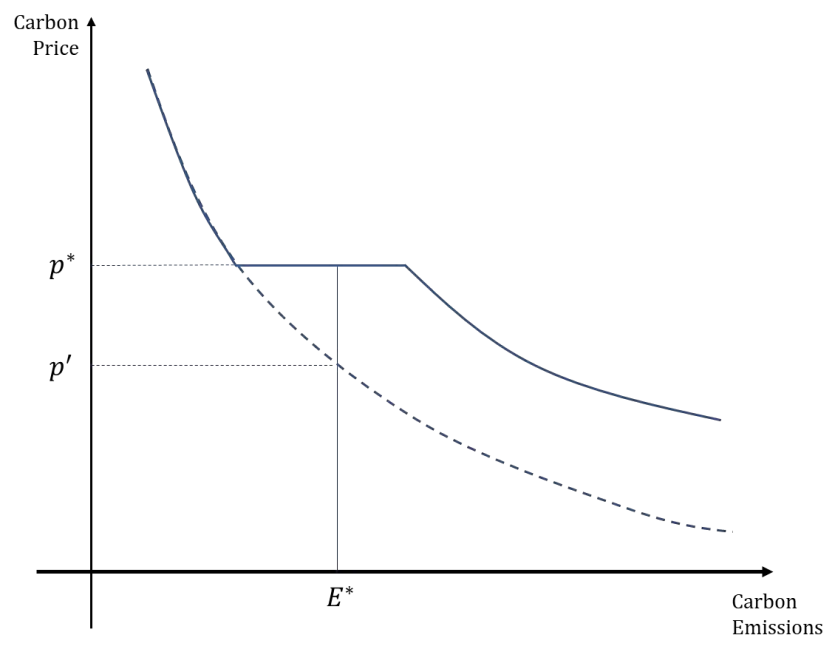

Figure $1 \mathrm{~A}$

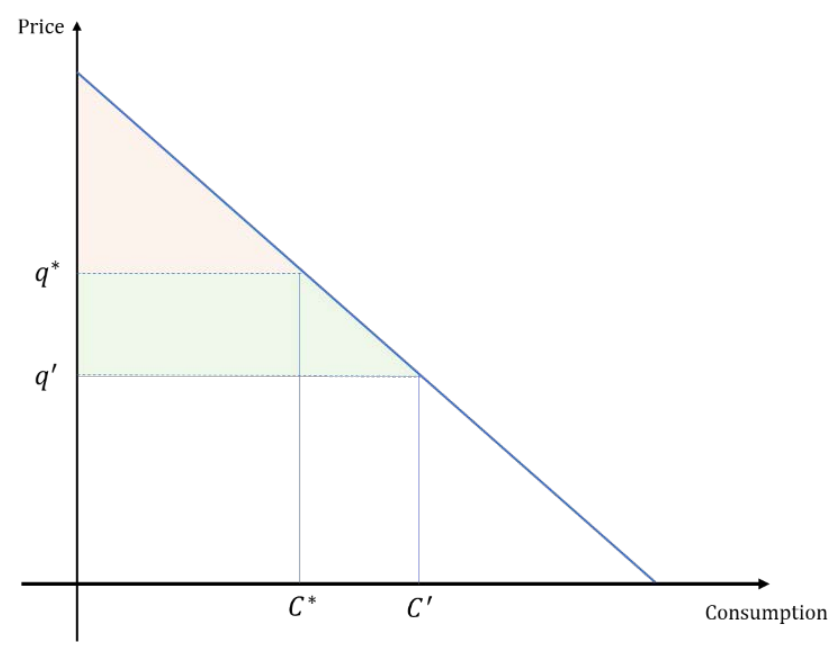

Figure 2B

\footnotetext{
${ }^{30}$ This formulation biases the analysis towards a regulatory intervention, since it assumes there is a well-defined, easily identifiable low emissions technology. In practice, as we note below, there are a myriad of decisions that affect emissions. The Stern-Stiglitz Commission recommended combining regulations with prices. Regulations can, for instance, proscribe coal burning electric generation; the prices will help induce low emission choices within non-coal technologies. See also the discussion below.
} 
Societal welfare (apart from the benefits of carbon reduction) is denoted by the indirect social welfare function $W=a_{R} V^{R}\left(q, q^{j}, Y_{R}\right)+\left(1-a_{R}\right) V^{N R}\left(q, q^{j}, Y_{N R}\right)$ where $q^{j}$ is the price of the jth good and $q$ is the price of all other goods, $V^{R}$ and $V^{N R}$ being the indirect utility of the rich and non-rich respectively, $Y_{R}$ and $Y_{N R}$ the income of the rich and non-rich respectively, $a_{R}$ the social weight put on the rich, with ${ }^{31} V_{q j}=-C^{j} V_{Y}$ and $V_{q}=-C V_{Y}$ where $C^{j}$ and $C$ are consumption in the carbon-intensive sectors and of all other goods, respectively (where for convenience we have dropped the subscript denoting the group), and $V_{Y}$ is the marginal utility of income. ${ }^{32} 33$ Now assume instead of relying just on prices, we introduce a regulation for sector $\mathrm{j}$ that requires producers to use the very low carbon technology. This shifts the supply curve of carbon, as depicted in figure $1 \mathrm{~A}$, so that the target emissions level can now be achieved at a low carbon price $\mathrm{p}^{\prime}<\mathrm{p}^{*}$. The constraint imposes an implicit higher shadow price on carbon in sector $\mathrm{j}$ : The effective shadow price of carbon in $\mathrm{j}$ (at least with respect to its choice of technology) is $p^{*}$, higher than $p^{\prime}$. This is the sense in which the regulation violates the principle of one price. Of course, sector j uses a "too low" carbon technology relative to the carbon price $p^{\prime}$; and it is the lower carbon intensity in that sector that allows for the carbon budget to be satisfied at a lower price. With the regulation in place, $\mathrm{p}^{\prime}$ is the price of carbon that achieves the desired reduction in carbon. At carbon price $p^{\prime}$, the cost of production of sector $\mathrm{j}$ would be lower at any choice of technique than at $p^{*}$ simply because of the lower carbon price, but in total, higher than it would be without the regulation because of the constraint of being forced to use the low carbon technology. In effect, while sector j confronts a higher carbon price, it gets a lump-sum rebate on the difference between $p^{\prime}$ and $p^{*}$.

\footnotetext{
${ }^{31}$ These are standard results concerning indirect utility functions.

32 We can explicitly incorporate loss aversion by writing the welfare function as depending on current prices po: $V\left(p-p_{0}, \ldots.\right)$, with $\left|V_{p}{ }^{+}\right|>\left|V_{p}{ }^{-}\right|$, i.e. the loss from an increase in price above the current level is greater than the gain from a fall in the price.

${ }^{33}$ Throughout this simplified analysis, incomes are kept constant, except that the proceeds of the tax are redistributed as a uniform lump sum.
} 
All products (with carbon emissions), with the exception of $j$, now have a lower price $q$ than without regulations, and on that account societal welfare is higher ${ }^{34}$. Of course, the regulation has increased the cost of production in sector $\mathrm{j}$, increased output prices in that sector, and introduced a distortion in the economy. On these accounts, societal welfare is lower. It is possible, however, that the former effect on social welfare outweighs the latter.

Carbon tax revenues are lower, by the amount $\left(p^{*}-p^{\prime}\right) \times E$, where $E$ is the level of emissions. The move from carbon prices $p^{*}$ to the regulation combined with carbon price $p^{\prime}$ leads to a change in consumer prices from $\left\{q^{*}, q^{* j}\right\}$ to $\left\{q^{\prime}, q^{\prime j}\right\} .{ }^{35}$ If we ignore distribution, the increase in utility from lower carbon prices is (from the indirect utility function) approximately $\bar{V}_{\mathrm{Y}}\left\{\left(\mathrm{q}^{*}-\mathrm{q}^{\prime}\right)\right.$ $\left.x C+\left(q^{* j}-q^{j}\right) C^{j}\right\}\left(\right.$ where $\left.\bar{V}_{y} \equiv a_{R} V^{R} Y\left(q, q^{j}, Y_{R}\right)+\left(1-a_{R}\right) V^{N R} Y\left(q, q^{j}, Y_{N R}\right)\right)$, which, if the shadow price of a dollar in the public sector is not too different from that in the private (so that $\bar{V}_{\mathrm{Y}} \approx 1$ ), is approximately equal to the difference in tax revenues, in a competitive economy with zero profits where the change in the value of output equals the change in the cost of production, the payments of carbon taxes plus the additional costs of production resulting from the regulation. But going beyond an infinitesimal tax, the gain in consumer surplus from the lowering of $q$ is strictly less than the loss in welfare from the distortionary regulation plus the loss in tax revenue: there is a deadweight loss. ${ }^{36}$ That is the essence of the Diamond-Mirrlees results on the desirability of production efficiency (the use of a single price in production.) If only efficiency were the issue (and there were no other second-best considerations), carbon pricing would thus be preferable.

\subsubsection{Direct distributional effects}

There are, however, both direct and indirect distributional impacts of a carbon tax. For simplicity, assume that the proceeds of the tax are used to reduce proportionately income taxes. If those who consume commodity j are disproportionately rich and those who consume the other goods are disproportionately poor, then the "tax-cum-regulatory" system imposes more of the adjustment burden on the rich and less on the poor, so that social welfare, as

\footnotetext{
${ }^{34}$ Even apart from any benefit from lower carbon emissions.

${ }^{35}$ For simplicity, we assume constant returns to scale technologies, so there are no pure profits/rents.

36 Illustrated in figure $1 \mathrm{~B}$ by the shaded area.
} 
measured by the change in $a_{R} V_{R}+\left(1-a_{R}\right) V_{N R}$, increases so long as the proceeds of the carbon tax at the margin are not distributed too progressively (that is, so long as the reduction in revenues from the lowering of the carbon tax doesn't have too regressive effects). The taxcum-regulatory policy drives down the overall carbon price, even if it creates an inefficiency, centered on good j. Hence the incidence of the tax-cum-regulatory regime is more on the rich: the rich disproportionately pay the cost of the regulatory inefficiency, because they consume a lot of $\mathrm{j}$, and the poor bear disproportionately benefit from the lower carbon price. ${ }^{37}$

In short, one has to weigh the distributional benefit against the production distortion to assess the desirability of the tax-cum-regulatory scheme vs. the pure tax. It is clearly conceivable that the former is preferred, especially if the carbon saving from the regulation is great and the distributional impacts are large.

\subsubsection{Indirect Distributional Effects}

There can also be indirect distributional impacts, as a result of the general equilibrium effects. The higher carbon tax may have an adverse impact on the relative demand for, say, unskilled labor (for example, if more carbon-intensive goods, like coal, are more unskilled-labor intensive), lowering wages of low-income workers. In first-, or even second-best tax theory, the government can provide a wage subsidy to low-wage workers (in general, and those directly impacted in particular ${ }^{38}$ ) that would offset this adverse distributional effect. Again, however, in practice implementing these additional subsidies is costly.

Indeed, implementing the offsetting subsidies may not even be feasible, given the limited information available to the government, which cannot monitor either effort or hours worked, the standard assumption in the theory of optimal taxation. ${ }^{39}$ Though any equalitarian social

\footnotetext{
37 Tax revenues decrease (a lower carbon tax times the same target level of carbon), necessitating a reduction in public expenditures (redistributions) or an increase in taxes elsewhere. If, for instance, there is a uniform increase in income tax rates, for the poor, the gains in the reduction in the carbon tax are greater than the losses from the increase in income taxes.

${ }^{38}$ Because of imperfections in labor mobility, adverse effects on those directly impacted are likely to be greater than on labor more generally.

${ }^{39}$ Thus, an individual may be a low-income worker because he is low ability, or because he is high ability but is exerting little effort or working fewer hours. If the government could monitor effort and hours worked, it could infer ability and impose a first-best lump-sum tax. See Mirrlees (1971).
} 
welfare function would like to distinguish among workers of different abilities, making such distinctions is costly and imperfect, and this is so whether one relies on self-selection mechanisms or direct screening mechanisms. As a result, policies that increase inequality in wages (the disparity between wages of skilled and unskilled workers) lower social welfare (Stiglitz (2018b)).

Whether the general equilibrium impact of a carbon tax is to lower wages of unskilled workers is an empirical question that may be hard to answer. It may reduce the demand for coal (emphasized by the Trump administration) and thus of coal miners, but it may also increase the demand for unskilled solar panel installers and thus increase (relative) wages of unskilled workers. Data suggest that for the US, the increase in demand for solar panel installers is greater than the loss in demand for coal miners, and if this pattern holds more generally, a carbon tax would be even more desirable than it would have been in the absence of these distribution effects. ${ }^{40}$

This example illustrates an important aspect of responding to the distributive impacts of a carbon tax: When there are an easily identifiable set of losers, it may be easier to design offsetting measures than when the population of losers is more diffuse. Identifying coal miners and designing policies to limit their losses may be relatively easy compared to identifying those consumers who disproportionately are adversely affected by a high carbon price.

\subsubsection{Horizontal inequities}

A very high carbon tax leads to horizontal differences among consumers who previously were similarly situated. Those who consume disproportionately more carbon goods are worse off. Thus, poor owners of carbon-inefficient vehicles who must use them extensively see the possibility that their real incomes will fall, and the value of one of their few assets, their vehicles, will decline as well.

\footnotetext{
${ }^{40}$ See Wei, Patadia, and Kammen (2010). Patrizio et al. (2018) describe how a well-designed "bio-energy with carbon capture and storage" (BECCS) strategy can actually preserve large numbers of jobs in the coal industry.
} 
The essential problem is that there is no way of compensating the high-carbon consumers that does not undo the objective of the carbon tax, which is to discourage consumption of carbonintensive goods. Assume, arguendo, that the government could observe the consumption patterns of each individual. It can then identify the individuals who are consuming high levels of carbon-intensive goods. But attempts to offset the loss of welfare with a grant based on their carbon consumption is, effectively, undoing the carbon tax. Only if it could see deep into the soul of the individual and ascertain who was a high-carbon consumer without looking at behavior could it accomplish the necessary redistribution within the framework of a carbon tax. This is clearly impossible. ${ }^{41}$

The issue just described increases in importance the larger the carbon tax, the larger the disparities in consumption patterns (which may be related both to income disparities and population heterogeneity) and the greater the societal loss aversion.

\subsubsection{Uncertainty about incidence, Horizontal Inequities and a Preference for a Smaller Carbon}

$\operatorname{Tax}$

There is a further, related set of arguments in favor of a mix of policies that include regulations with an implicit higher carbon tax in some uses, but results in a smaller carbon tax overall. ${ }^{42}$ Assume, as in the previous paragraphs, that there is unobservable individual heterogeneity making it impossible for government to compensate each individual for the carbon tax he has paid. All that can be done is to compensate the average individual. The individual himself may not know enough about the set of available technologies ex ante to know the magnitude of the price increases to be expected at each level of carbon price. But ex ante, the imposition of a

\footnotetext{
${ }^{41}$ That is, the only signal that high-carbon preference individuals are deserving of additional compensation is their consumption of carbon-intensive goods. Using that as a basis of compensation would, of course, undo the effects of the carbon tax.

${ }^{42}$ The distinction between the discussion of this section and our earlier discussion of individual heterogeneity is this: the earlier discussion focused on the consequences for social welfare of the inability to offset the differential effects on different individuals; here we focus on the fact that individuals themselves may now know enough about the structure of the economy to be able to predict the consequences of a particular policy on their own wellbeing. (In the former model, individuals understood the consequences, but the government couldn't ascertain who was affected in which way). This uncertainty about the consequences of a policy change means that individuals' ex ante expected utility is lower-it has a social cost. It can also have political consequences: it can (rationally) lead to opposition to the policy change.
} 
carbon tax can be thought of as mean income preserving spread, in the sense that, on average, all of the income collected will be paid back, but that will not be true for any particular individual, who may get back more or less than she paid. It should be clear that if individuals are sufficiently risk (or loss) averse, then all individuals might oppose the carbon tax because their expected utility, taking into account the uncertain incidence ${ }^{43}$, is lower. And the greater the carbon tax, the greater the loss in welfare. ${ }^{44}$ In some cases, where there is an explicit green technology-renewable energy - one may be able to induce the switch to the "greener" technology more efficiently, with less redistributive consequences and with less uncertainty, through a subsidy for a particular class of technologies or a regulation than through a general carbon tax. ${ }^{45}$

So too, there may be more uncertainty associated with the consequences of a carbon tax than with that of particular regulations. This is the case, for instance, for a regulation that specified a particular alternative technology, with a predictable impact on costs through the economic system. This may be the case even for the government. There is what has been called in other contexts instrument uncertainty ${ }^{46}$.

A regulation that simply specifies the use of the low emissions technology (when such a technology can be identified) may, accordingly, be preferable to the use of a sector-specific carbon emissions tax. ${ }^{47}$ Thus, a portfolio of actions entailing "low uncertainty regulations" and

\footnotetext{
${ }^{43}$ That there is such uncertainty is obvious: economists disagree markedly over tax incidence.

${ }^{44}$ There may be still greater uncertainty because of the possibility of new technologies being introduced as a result of a carbon tax. The next section will deal explicitly with induced innovation.

${ }^{45}$ Instrument uncertainty may lead to the preference for sectoral regulatory measures rather than sectoral specific taxes, as the next paragraph illustrates. See, however, the discussion elsewhere in this paper, including at the end of section 3.1.6., on the benefits of combining price and regulatory mechanisms.

${ }^{46}$ For instance, the government may not be sure of the level of carbon tax required to achieve, say, the Paris goals, or precisely what price of carbon will induce the use of the low emissions technology, in the example earlier in this section. Instrument uncertainty matters: there is a societal cost (in additional distortions in the price of the jth good) in imposing a tax beyond the necessary level. A government commitment to obtaining that objective through a carbon tax may impose a high level of risk on consumers and producers.

In the context of macroeconomics, the role of instrument uncertainty in affecting the desirability of price vs. quantity measures has been discussed in Greenwald and Stiglitz (1989). See Hepburn (2006) for a review on instrument choice under uncertainty. Risk can be mitigated by the kinds of "safety valve" measures discussed in section 5.1 .

${ }^{47}$ It is straightforward to formalize the losses associated with these uncertainties and to compare the consequences of the use of a price vs. a regulatory intervention.
} 
"a relative low carbon tax" can, in terms of ex ante expected utility, be preferred to just a carbon tax (yielding the same expected reduction in carbon emissions) by all individuals

\subsubsection{Alternative ways of achieving carbon reductions consistent with distributional objectives}

A natural question is, are there other ways of achieving carbon reductions consistent with distributional objectives? The government might, for instance, subsidize the consumption of the non-j goods and tax the consumption of $j$, achieving the same consumption prices and therefore the same distributional effects. Even this intervention violates the "one price of carbon for all uses," but at least it entails a price rather than a regulatory intervention. ${ }^{48}$

Of course, in the absence of uncertainty and transaction costs, and with perfect information, one can achieve identical outcomes through either tax or regulatory interventions. ${ }^{49}$ But the solution entailing taxes with offsetting subsidies is more complicated: every sector except j faces both a carbon tax and a consumption subsidy, and the jth sector faces a carbon tax and a consumption tax.

While this section has emphasized the use of regulatory measures to complement a carbon tax to enable lowering the level of the carbon tax, there are other actions the government can take with similar effects. Any public investment, zoning regulation, or other public action that results in a shift to the left in the overall supply of carbon at any carbon price lowers the requisite carbon price. The "single carbon price" rule might suggest that in all of its public investment and regulatory decisions, the government evaluates alternatives using that carbon price. This analysis suggests that for certain investment or regulatory decisions, it may want to use a higher shadow price if there are "favorable" distributive benefits, either directly or indirectly, as

\footnotetext{
${ }^{48}$ Some of the public discourse concerning fuel standards revolves around similar issues: for instance, some have suggested that lowering fuel standards would have a positive distributional effect (Holland, Hughes, Knittel, 2009), though we noted earlier that transport may be one sector in which increasing energy prices would have a positive distributional effect.

For an earlier discussion of how to make a carbon tax reform progressive, see Klenert and Mattauch, 2016. 49 This is a general result: under these conditions, there is no compelling case against regulation and for price interventions. It is only when one introduces imperfect and asymmetric information, uncertainty, and transactions cost that one can argue for one instrument over another. But when this is done formally, the case for price interventions is typically less compelling than economists have assumed. See, e.g., Weitzman $(1974,1977)$ and the more extensive discussion in section 5 .
} 
a result of the lower carbon price. A greater investment in public transportation might thus be doubly desirable, being particularly beneficial for the poor, and at the same time enabling the equilibrium price of carbon to be lower than it otherwise would have been. ${ }^{50}$

\subsubsection{Putting the result in perspective}

As we noted in the introduction, the result just derived can be viewed as a specific application of a more general result in the theory of optimal taxation and expenditures: when there are distributive effects that cannot be undone by commodity taxes (including type specific factor subsidies), production efficiency is in general not desirable. ${ }^{51}$ Here, it would be desirable to tax carbon emissions in the jth sector at a higher rate. This would be the case even if there were a continuous technology choice in the jth sector. There are instances in which this can be (and has been) done: we can charge a higher price for aviation fuel (consumed more by the rich) than for gasoline. More generally, if we can identify a set of goods which are more carbon intensive and more consumed by the rich, it would be desirable to impose higher taxes (including higher carbon taxes) on these goods. And the same holds for intermediate goods which are used in the production of final goods which are consumed disproportionately by the rich.

The discrete change in technology in sector $\mathrm{j}$ (and thus of emissions) might, of course, naturally lead to a "corner" solution, where the tax is set at just the level to induce the lower level of emissions. Further increases in the jth sector carbon tax would yield lower marginal benefits. ${ }^{52}$

If that were all that there were to the matter, we could achieve the result either by a regulation or a sector specific carbon tax set at the level to just induce the use of the low emission technology. But in practice, matters are more complicated. Because the critical tax may differ

\footnotetext{
50 This argument follows that of Stiglitz (2018b), which also analyzes the distributive implications of public investment, showing the desirability of the use of differential shadow prices.

${ }^{51}$ As we noted earlier, this holds too if there are other restrictions on taxation, e.g. on profits and rent taxes, especially if these restrictions have distributive consequences.

52 The optimal tax problem is beset by non-convexities and discontinuities, as Mirrlees (1971) and much of the subsequent literature has recognized. See, e.g. Arnott and Stiglitz (1988).
} 
from firm to firm, a different tax would have to be set for each firm. And because the critical tax might differ over time, it would have to be continuously reset.

In many cases, however, there are multiple subtle choices concerning techniques of production, and implementing separate regulations for each of these may be virtually impossible. To induce firms to make the right choices, one has to rely on the use of a carbon price. This argues for combining regulations with carbon prices, as the Stern-Stiglitz Report advocates. ${ }^{53}$

\subsection{Some Political economy concerns}

Not surprisingly, there are political consequences arising from the possibility of adverse (uncompensated) distributional effects. ${ }^{54}$ Individuals are particularly sensitive to high new taxes (consistent with the theory of loss aversion), and political discourse often centers on the individuals who are likely to be hurt. Large losers from a carbon tax will campaign against the carbon tax. As we noted earlier, there is typically uncertainty about the ultimate effect of a tax, and thus large numbers of individuals, even possibly a majority, may face a lowering of their ex ante expected utility, and thus oppose even a tax with lump sum rebates. The regulation, by keeping the carbon tax to a lower level, reduces the distributive effects, except for those associated with sector $\mathrm{j}$, and may accordingly mitigate these adverse political effects. ${ }^{55}$ Thus the tax-cum-regulatory policy may be (more) politically robust.

Moreover, both among recipients and non-recipients of subsidies, there may be beliefs (rational or irrational) concerning what are acceptable and non-acceptable subsidies, taxes, and regulations, all of which are particularly relevant to the political economy of carbon taxation. It may be acceptable to have a hidden subsidy to coal, which leads to higher wages of coal

\footnotetext{
${ }^{53}$ Recall our earlier discussion focusing on problems associated with implementation and instrument uncertainty. There is a related point of regulatory circumvention: innovations which comply with the regulation but are less effective in reducing carbon. It may be difficult for the government to continuously adapt the regulations in response to changing technology. This is not the case, however, for regulations that focus directly on emission levels.

${ }^{54}$ Even when there are compensations, as we noted in section I, voters may not believe that there can be a credible commitment to the continuation of such subsidies. Preventing time inconsistencies in this arena may be more difficult than in the context of investments, described elsewhere in this paper.

${ }^{55}$ Because sector $\mathrm{j}$ is (by assumption) a sector that is disproportionately consumed by the rich, the distributive impacts may be politically "welcome," and even more so if that sector has a high level of carbon emissions. It will have political legitimacy.
} 
miners, but unacceptable to give coal miners an explicit pay check. (Behind views of what is and is not acceptable are "narratives": coal protection may be justified because it is protecting the industry against unfair competition from abroad, while outright subsidies are seen simply as handouts. And the objection to handouts may not just be "moral," but political-where do we draw the line in who gets handouts?) While from an analytical perspective, there may be limited or no difference amongst these alternatives, behavioral economics has shown that framing and perceptions matter. Thus, it may be acceptable to stop firms that impose large costs on others (big polluters) through regulation, but not acceptable to "allow" them to pollute, simply by paying a price to do so. ${ }^{56}$ Among environmentalists, a standard criticism of an environmental tax is that it allows those with money to destroy the environment: it puts a price on something that should be priceless.

\subsubsection{Endogenous Preferences and Behavioral Economics}

In doing so, it changes attitudes towards the environment and its protection; it can change preferences in a fundamental way. As we noted earlier, a recent strand of behavioral economics has emphasized the determination of "deep preferences," what individuals actually care about. While there has not been much research into the relative impact of prices vs. regulations in changing "deep preferences," 57 from what has been observed in other contexts, putting a price on the environment may make it more acceptable to "abuse" it, i.e. to engage in emissions, while strong regulatory constraints may help create a norm of protecting the environment.

Similarly, in many countries, for instance, there has been a change in attitudes about the use of plastics, and especially plastic bags, a change in which grocery store policies may have played an important role, as they increasingly switched to paper and reusable bags. The switch had

\footnotetext{
${ }^{56}$ See Sandel (2012) and Bowles and Polania-Reyes (2012). For a somewhat contrasting view, see Caney and Hepburn (2011). Klenert et al. (2018) emphasize the importance of framing policy proposals in ways that generate political acceptability

57 There is some recent research on the behavioral impact of carbon taxes. Similar to the day-care experiment, Lanz et al. (2018) show experimental evidence on how carbon taxes can crowd out pro-social motivation to consume less carbon-intensive products. Mattauch, Hepburn and Stern (2018) provide a framework to adjust carbon taxes taking into account such change in social preferences. While these analyze the behavioral impact of carbon taxes, there is no evidence on relative impact on behavior of a carbon tax vis-à-vis regulation. .
} 
salience. It was an everyday reminder of the importance of the environment, and it thereby helped reinforce pro-environment attitudes and values. Even when grocery stores started charging for plastic bags to induce the switch, it was welcome-a sign that the store was environmentally sensitive-rather than greeted with the hostility that it would have received a quarter century ago. In turn, the use of paper bags helped spread a culture of environmental sensitivity. In these cases it was a small price (though from some perspectives, going from a free bag to charging a few pennies is a large change) that induced changes in behavior, leading in turn to changes in norms, while in other countries, it was regulations that brought about the social change. Regulations moving the economy towards green light bulbs, for instance, might shift consumption patterns far faster than a change in price. ${ }^{58}$ Social coordination-creating new norms - may not be optimized by changes in prices, partly because such changes in prices do not in general signify changes in norms. By contrast, a regulatory induced change to paper bags and green light bulbs more clearly reflects a new societal norm.

For all these reasons, the combination of regulations and prices might be preferable on both utilitarian and political economy grounds.

\subsubsection{Diffuse vs. concentrated costs}

But countering these political economy arguments are those that go in the opposite direction: while the impacts of general carbon taxes are diffuse, those of a regulation (e.g. on sector $\mathrm{j}$ ) are more concentrated, and a standard political economy argument holds that the problem of the "public good" of lobbying is more easily overcome when impacts are concentrated, i.e. there will be lobbying by the jth sector to water down the regulations and to make sure that they do not keep pace with changes in technology. On the other hand, with some industries so much more polluting than others, and therefore more affected even by a uniform carbon tax, these high polluting industries have an incentive to lobby against any carbon tax at a significant rate or for an exemption for their industry, greatly weakening the effectiveness of carbon pricing. In

\footnotetext{
58 This may be particularly true in those instances where it is hard to explain consumption patterns on the basis of models of economic rationality, e.g. individuals could save money by switching to greener products.
} 
their campaign against the tax, they will, of course, emphasize adverse effects on ordinary individuals. In many countries such an unholy alliance has been able to stymie green policies. Especially as the importance of climate change has come to be generally recognized, seemingly distributionally sensitive green policies, with regulations targeted at the worst offender, may garner more political support.

Some have argued that by linking the carbon tax with a uniform direct dividend of the revenues received one can change the political economy of the carbon tax. Such a policy would, on average, be strongly redistributive, and many have argued that somehow, this form of redistribution would be acceptable (because it is associated with the public good of reducing carbon emissions) when comparable redistributions would not be. These alleged political economy advantages, proponents claim, more than outweigh the inefficiency associated with provided lump sum payments to the household sector combined with distortionary taxation to recover the revenues lost, that might otherwise have been spent, say, on green infrastructure.

There is another political argument in support of a carbon tax with proceeds redistributed as lump sum payments: It could simultaneously garner support of both progressives with equalitarian social preferences and conservatives with a procedural preference for markets, who see the tax as avoiding heavy-handed government interventions. ${ }^{59}$

\section{Innovation}

The nature of the optimal price path is a subject of some controversy, with some arguing for a slow path of price increase, giving time for individuals to adjust; some suggesting that optimal (discounted) prices being the same over time, and others arguing for a fast path-or even a higher price in the short run than the long ${ }^{60}$. The Stern-Stiglitz Commission itself seemed somewhat agnostic on the issue, though it called attention to both the importance of adjustment costs and innovation:

\footnotetext{
59 This argument is, of course, far more salient in some countries, like the United States, than in others.

${ }^{60}$ See Sinclair $(1992,1994)$ and Ulph and Ulph (1994) for an early discussion. 
"Efficient carbon-price trajectories begin with a strong price signal in the present and a credible commitment to maintain prices high enough in the future to deliver the required changes. Relatively high prices today may be more effective in driving the needed changes and may not require large future increases, but they may also impose higher, short-term adjustment costs. In the medium to long term, explicit price trajectories may need to be adjusted based on the experience with technology development and the responsiveness to policy. The policy dynamics should be designed to both induce learning and elicit a response to new knowledge and lessons learned. Price adjustment processes should be transparent to reduce the degree of policy uncertainty..."

The objective of the discussion here is to develop a better understanding of the argument for a trajectory with a particularly high price in the short run to spur innovation. (Note that the previous section focused on the overall level of carbon prices-arguing that the use of regulations may allow the carbon price to be set at a lower level than otherwise. Here, we are concerned with the trajectory of prices, given a particular set of regulations, that is, whether optimal prices increase or decrease over time. Analogous issues arises with the time trajectory of regulations.) $)^{61}$

The argument for the middle position-a constant price in today's dollars, which entails prices increasing exponentially at the rate of interest-is, as we noted earlier, derived from the nature of climate change itself. More generally, there is some smooth increase in expected marginal damage per ton as cumulative emissions increase. While the shadow price is not an explicit function of time, it is an explicit function of cumulative emissions, which is itself a function of

\footnotetext{
${ }^{61}$ Space limitations do not allow us to consider the relative merits of prices vs. regulations in inducing innovation. There is, however, a direct analogue to the question posed here: the trajectory of regulation, i.e. at what pace regulatory standards are optimally tightened over time. Regulations can be translated into shadow prices, and once that is done, the analysis here is directly applicable.

While the overall lower level of carbon prices will induce less innovation in reducing emissions in those sectors, the regulation in the high carbon sectors, especially if well-designed (e.g. targeted at limiting emissions), can be very effective in reducing emissions in these sectors. Given the non-convexities associated with research, it may be efficient to focus research centered on reducing emissions in the high emissions sectors.
} 
time. As we approach the limiting situation, where we are able to contain increases in atmospheric carbon concentrations, then the (discounted) price converges to a constant.

Popular discussions focus on politics and adjustment costs. Politically, societies are averse to quick changes, partially for reasons already given. Moreover, quick changes have large costs of adjustment. Conventional economic costs of adjustments by themselves cannot justify a timevarying price: individuals will respond slowly if there is a cost of adjustment. But they need to be guided in their adjustment by the right shadow prices. But because of the macroeconomic externalities associated with the adjustment process, the macro dynamic process is not in general efficient. ${ }^{62}$ Moreover, as the previous section explained, individuals themselves may not be sure about the costs that they will bear in the process of adjustment ${ }^{63}$, and risk and loss aversion might then result in large majorities opposing any pricing scheme, even if there were, say, lump-sum rebates that sufficed to compensate the average individual. Achieving an efficient, equitable, and politically acceptable adjustment process may accordingly entail timevarying prices - with a presumption that prices adjust slowly to the long-run equilibrium in order to spread the adjustment costs out over time. ${ }^{64}$

Here I want to present an argument to the contrary: that it may be desirable to have a higher carbon price in the short run than in the long run.

\subsection{Learning by doing and inducing a shift in technology}

The argument derives from the benefits from innovation that might be induced by a highcarbon price in the short run, benefits which extend over time. There are large fixed costs of

\footnotetext{
62 That is, a firm in laying off a worker (say in response to a high carbon tax making a particular technology uncompetitive) doesn't take fully into account the costs imposed on the workers, e.g. in finding a new job, nor does he take into account the induced unemployment that might result as that worker cutbacks his consumption. For a broader discussion of macroeconomic externalities, see Jeanne and Korinek (2010).

63 This argument is analogous to the one presented earlier concerning uncertainties associated with the impacts of a change in the carbon price across individuals.

${ }^{64}$ There may, in additional, by intergenerational aspects. The generation in which the aggressive transition to a green economy begins may bear disproportionately the costs, because of changes in asset values. Slower transitions modulate the impacts on these asset prices. The generation that is at the onset of a green transition may bear additional fixed costs in designing new alternative technologies. It is problematic whether market mechanisms will ensure that these costs will be shared across generations, and it is also problematic whether government will engage in offsetting intertemporal redistributions.
} 
switching technologies, and only large changes in relative prices can induce a change in technology. Once that change is effected, there would be large switching costs to return to a high carbon technology, and especially if there is learning by doing, so that the low carbon technology continues to improve relative to the high-carbon technology. Learning by doing argues that as a result of using a technology, there are improvements in its productivity (Arrow, 1962; Stiglitz and Greenwald, 2014). The theory of localized learning argues that improvements in one technology-for example, a low-carbon technology-spill over at best imperfectly to other technologies, say, the high carbon technology (Atkinson and Stiglitz, 1969, Acemoglou, 2015). ${ }^{65}$ This implies that the prices required to maintain a low carbon economy can be lower than those required to induce a switch. ${ }^{66}$

When there are spillovers to others from learning, the benefits of learning will not be fully appropriated by the parties making the decisions. In making their production decisions, firms won't take into account the learning benefits that will not be appropriated by the firm itself. The optimal carbon price trajectory has to "correct" this externality.

\subsection{A Simple Model: The Theory of Induced Innovation}

A simple model that captures and expands on some of the insights of the previous paragraphs is based on the theory of induced innovation ${ }^{67}$, where firms have a choice between efforts

\footnotetext{
${ }^{65}$ In the case of explicit research programs, in principle we could introduce a research subsidy to encourage "green" research, and some of the earlier literature argued for the use of such a subsidy (as opposed to a production subsidy) precisely on the grounds we are arguing for here (Acemoglou et al., 2012; Fischer and Newell, 2008; Gerlagh, Kverndokk and Rosendahl, 2014, and Tvinnereima and Mehling (2018). With learning by doing, however, there is no explicit research program. It is a by-product of decisions about production, which are affected by carbon prices. The social value of the learning associated with increased production implies that there is an additional argument for (early) subsidies of production using the green technology. The analysis of the following section implies that the magnitude of the green production subsidy may decline over time. Stiglitz and Greenwald (2014) have emphasized the role of government subsidies in the presence of such learning spillovers.

${ }^{66}$ For a similar result, also exploring the policy implications, including for price trajectories, see Kalkuhl et al. (2012).

67 There is an old and distinguished literature, dating back to the work of Fellner (1961), Drandakis and Phelps (1966), Samuelson (1965), Kennedy (1964), Habakkuk (1962), and more recently revived by Acemoglu (2002, 2010) and Stiglitz (2006, 2014, 2018a). The model developed here is more general and less parametric than many of the other recent models of induced (or directed) innovation. There are other differences to which we call attention as we develop the model.
} 
directed at reducing carbon emissions and labor costs. We model it by assuming output is a function of labor $L$ and energy $E$, and innovation makes each unit of labor more productive (labor augmenting innovation, denoted by an increase in $\lambda$ ) or energy more productive (energy augmenting innovation, denoted by an increase in $\mu)^{68}$ in the production function

$$
Q=F\left(\mu^{t+1} E, \lambda^{t+1} L\right)
$$

We assume for simplicity that energy use translates directly into carbon emissions. (A more complicated version of this model would focus both on innovations reducing energy per unit of output and emissions per unit of energy.) We make use of the well-established concept of the innovation possibilities curve, postulating that there is a tradeoff between $\mu$ and $\lambda$, as depicted in Figure 2: One can only have more energy-augmenting technological progress by giving up on labor-augmenting technological progress. 69

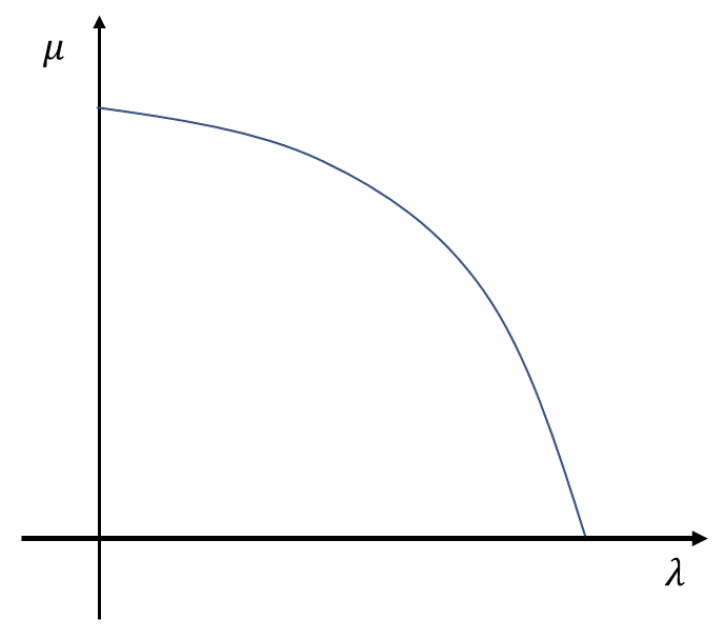

Figure 3

(3.2) $\mu=Z(\lambda), Z^{\prime} \leq 0, Z^{\prime \prime} \leq 0$

\footnotetext{
${ }^{68}$ While (3.1) does not embed the principle of localized technological progress, it is easy to extend the model to incorporate this, with each technology having its own value of $\lambda$ and $\mu$.

${ }^{69}$ For simplicity, we have dropped the time superscript.
} 
We assume each period, the innovation curve is defined relative to the state of knowledge of the previous period.

We assume a large number of symmetric firms, so each firm takes future period's wage and energy costs as given. With a symmetric equilibrium, all firms pursue the same innovation strategy. We assume that knowledge produced at $t$ for $t+1$ becomes publicly available at $t+2$. A firm only focuses on the "private" benefits of innovation, and these occur at time $t+1$, because after that the knowledge is public. ${ }^{70}$

A standard result in the theory of induced innovation is that the firm chooses the technological innovation mix which minimizes cost, and the cost-minimizing point is that where the elasticity of the innovation curve $=d \ln Z / d \ln \lambda=$ relative shares $\left(\mathrm{s}_{\mathrm{L}} / \mathrm{s}_{\mathrm{E}}\right) \cdot{ }^{71} \ln n$ ovation is directed at the factor whose share is relatively large. If the relative labor supply were to diminish, and the elasticity of substitution between labor and energy were less than one, then the share of labor would increase, and innovation would be directed more at augmenting labor. ${ }^{72}$

The sequence of carbon prices (assumed to increase the cost of energy) thus affects the energy efficiency at every date-an increase in carbon prices at t increases energy efficiency at every subsequent date. The value of reducing energy (carbon emissions) today is compounded by the savings in subsequent dates. The market "bias" and level of investment in innovation are inefficient because the individual firm doesn't take into account future benefits, since, by assumption, these innovations move into the public domain the following year. ${ }^{73}$

\footnotetext{
${ }^{70}$ This is a crucial difference between this model and much of the more recent literature, where each entrepreneur has to solve a complicated intertemporal maximization problem. (In a more fully articulated version of this model, each entrepreneur would take as given the technological opportunities to be available in subsequent periods as a result of the innovation by others, and might decide to augment that set by his own technology. Given the symmetry assumptions, what he does is identical to what others do.)

${ }^{71}$ Note, as in the case of learning by doing, that it is the price of carbon as confronted by the firm, that matters. As we noted earlier, the market distortions that arise here cannot be effectively addressed by having a general $R$ \& $D$ subsidy, though obviously a subsidy limited to energy augmenting innovation would change the allocation of R \& D between energy augmentation and labor augmentation.

72 In some of the older literature (Habakkuk, 1962), it was suggested that innovation was directed at increasing the productivity of labor because it was "scarce." This analysis suggests what is relevant is the relative share.

${ }^{73}$ More generally, there is no presumption that markets are efficient either in the level of investments in innovation or in the direction. This is true in virtually any model of innovation. (See Stiglitz and Greenwald, 2014).
} 
The social value of, say, a percentage reduction in carbon emissions $\Delta$ when the shadow price of carbon emissions is $p_{s}$ (assumed to be fixed at all dates) is $p_{s} \Delta \Sigma C_{t}$ where $C_{t}$ is the carbon emissions at time t. Since the carbon emissions will be converging to zero, the social value of reduced carbon emissions falls over time. Hence, as we set the market price of carbon to reflect both the shadow cost of emissions today and the social value of induced innovation, it is clear that the optimal carbon price falls over time. ${ }^{74}$

Obviously, this result depends on the time profile of $p_{s}$. If the shadow price of carbon is increasing over time because of increasing concentrations of carbon, then it is possible that $\sum \mathrm{p}_{\text {st }} \Delta \mathrm{C}_{\mathrm{t}}$ might increase for a while. However, at least as we approach the steady state, where we've been able to contain increases in atmospheric carbon concentrations, so $\mathrm{p}_{\mathrm{st}}$ converges to a constant, the value of innovation diminishes.

While this argument implies a price trajectory with a high initial price, doing something is better than doing nothing. The political economy-resistance to an initially high carbon tax-may, in the end, be dispositive. ${ }^{75}$

\subsection{Behavioral Economics Effects}

While the analyses presented so far in this section is based on standard models of innovation with rational individuals and profit-maximizing firms, there are further arguments for a high initial price of carbon based on the kinds of behavioral economics considerations discussed at the end of the last section. One has to engineer a major change in mindset from a fossil fuel economy to a green economy. Incremental changes in prices may not do that. Large changes do, especially when they are centered around things that are salient in an individual's life.

This is a market failure in addition to the market failure associated with global warming. But it is a market failure that public policy cannot ignore.

${ }^{74}$ Distributive effects are being ignored, either because there is a lack of concern about distribution or because there are adequate instruments for undoing the effects. The significance of redistributive effects could also change over time, reinforcing or offsetting the above conclusion.

${ }^{75}$ Countering this political argument is the one made earlier: early investments in green innovation may help solve the time inconsistency problem, garnering sustained support for green policies. 
That's why regulations forcing firms to, say, increase automobile energy efficiency or use green light bulbs have sometimes proven more effective than price incentives. ${ }^{76}$

A high early price of carbon may also change the behavior of the fossil fuel industry, inducing them to explore less for oil, and the resulting higher prices of fossil fuels may help reinforce the move to a green economy. ${ }^{77}$

\section{Uncertainty and a Revised Weitzman Price Quantity Perspective}

In the context of climate change, there is considerable uncertainty, e.g. about the magnitude of the links between greenhouse gases and climate change and that of the links between any instrument and greenhouse gas emissions. The latter uncertainty has led some environmentalists to argue for quantitative restrictions on emissions. Earlier, Weitzman (1974) delineated conditions under which such restrictions would be preferable to a simple price intervention. ${ }^{78}$

One way of understanding this is to note that while the standard result argues for a single price of carbon in all places, for all uses, at all dates, the (appropriate shadow) price differ depending on the state of the world. There is much we don't know: the effects of any policy on emissions or the effects of emissions and carbon concentrations on climate change, and the full effects of climate change on well-being. Thus, as we learn more about the state of the world the carbon price adjusts. In fact, the best we can do is to announce a carbon price today and a limited state-dependent sequence of prices going forward. Weitzman's analysis focused on a oneperiod world, where either price or quantity has to be set before we know critical information about the state of the world. The price we set may be either too high or too low, given the true

\footnotetext{
${ }^{76}$ Of course, as always, one has to offset these benefits with the short term distortionary costs that may arise particularly from a high (implicit) carbon price in a particular sector or against a particular technology. Karplus et al 2013, for instance, argue that there is a high cost to US vehicle fuel economy standard within a standard computable general equilibrium model, without innovation and without behavioral economics effects.

77 In principle, of course, exploration is based on the whole time path of carbon prices, so that seeing (credible) high future prices leads to less exploration. But there is a large literature suggesting that firms are myopic, paying more attention to the economics of the moment (today) than possible future scenarios. Moreover, oil companies may believe that if they succeed in finding large oil deposits, the fear of stranded assets will curtail the imposition of excessively high carbon prices.

${ }^{78}$ See Stiglitz (1986) for a standard textbook treatment.
} 
state of the world; and so, too, for the quantity. ${ }^{79}$ Weitzman derives conditions under which if we have to pick either a single price or a single quantity, picking a quantity would be preferable. In earlier policy discussion, this debate has loomed large, with many environmentalists arguing for cap-and-trade because it centers policy on the objective of concern, the level of concentration of carbon dioxide, and avoids the problems posed by price-instrument uncertainty. The Stern-Stiglitz report does not weigh into this debate, simply stating

There are different ways to introduce a carbon price. Greenhouse gas (GHG) emissions can be priced explicitly through a carbon tax or a cap-and-trade system.

As we have noted, the level of climate change and its consequences is of ultimate concern, and this is related (in an uncertain way) to the concentration of greenhouse gases in the atmosphere. This in turn is a result of emissions that occur over a long period of time. Weitzman's analysis applied to a one-period problem (where welfare was, in effect, related to the flow of pollutants rather than here, to a stock.) There is not only instrument uncertainty but also uncertainty about the relationship between atmospheric concentration and social consequences. The discussion in this section highlights some additional considerations that need to be brought to bear beyond those highlighted by Weitzman and some of the subsequent research extending his work into a dynamic context.

As we learn more about the relationship between price (pollutant charge) and emissions (related, in turn, to the technology of emissions abatement), and about the consequences of climate change and the relationship between climate change and atmospheric carbon concentration, the target level of atmospheric concentration to be achieved needs to be revised. ${ }^{80}$ If we use a price mechanism, it means that the price charged is revised. The same, of course, could be said for the quantities approach. Accordingly, even when the quantities can

\footnotetext{
${ }^{79}$ Having a single price for all states of nature is analogous to a restricted tax regime where the same tax rate has to be imposed on a range of products (in an unrestricted tax regime, every product-distinguished by every feature-would have its own tax; this is obviously impractical, so, for instance, all automobiles, or all automobiles of a certain size, face the same tax rate). Dasgupta and Stiglitz (1971) show that when that is the case, in general, production efficiency may not be desirable, i.e. having just a carbon tax may not be optimal.

${ }^{80}$ See Hoel and Karp (2001, 2002) and Pizer (2002).
} 
be made state dependent, a pure quantities-based framework does not result in perfect consumption (emissions) smoothing.

The key trade-offs in this dynamic formulation have to do with asymmetries of information, the speed of government response, the magnitudes of the underlying uncertainties including instrument uncertainty, and the relative ease (cost) of adjusting prices vs. quantities. ${ }^{81}$ Some limiting cases may be illuminating. 82

If, for instance, there were no asymmetries of information, no uncertainties about the consequences of setting a particular price, and government could respond instantaneously as new information about technology or the consequences of atmospheric concentrations increase by adjusting either prices or quantities, then (as in the standard one period model) a price and a quantity approach are equivalent: both are state contingent, and each would be set to generate exactly the same time profile of emissions and consumption.

If there is no uncertainty about the (expected) marginal social damage of emissions at each date, then obviously a carbon price reflecting the (expected) marginal social damage of emissions achieves the optimal results. Assume, however, the government does not have full information on all the technologies relevant to emissions and emissions abatement. ${ }^{83}$ Then in the quantities approach, the government would, on the basis of its impartial information, have to set forth an uncertain time path of quantities (to be revised as it learns more about actual emissions). With bankable caps (at the right interest rate), the price and quantities approaches

\footnotetext{
${ }^{81}$ The latter has featured prominently in macroeconomics, where the menu cost literature (Sheshinki and Weiss (1977), Akerlof and Yellen (1985a, 1985b, and Mankiw (1985)) has emphasized the cost of adjustment of prices, while other literature has suggested that such costs are not significant, not large enough to explain macroeconomic fluctuations (Golosov and Lucas, 2007) and stressed adjustment costs and uncertainties related to quantities (see, e.g. Greenwald and Stiglitz 1989).

${ }^{82}$ As Karp and Traeger (2018) observe, in many cases, the choice between price and quantity regimes can, even in a dynamic setting, be put into a generalized version of Weitzman, where what matters is the relative slopes of the marginal damage and marginal cost curves. The discussion below will highlight some of the special assumptions underlying their analysis.

There is one more dimension of optimal intergenerational policies that has perhaps received insufficient attention but which we will not be able to pursue here: intertemporal risk trade-offs. Increasing expected utility this period by reducing risk may well increase the risk that will have to be borne by future generations.

83 If the government is not certain of current and future abatement cost functions, it can only be certain of the appropriate marginal social cost of carbon if the social damage function is horizontal.
} 
would, of course, be equivalent-the private sector in effect using its information to "correct" inappropriate caps set by the government.

Assume now that there were some clear threshold above which climate change was intolerable (but below which it was manageable), so that we had a clear target for atmospheric carbon concentrations, but again the government has less information about abatement technology than the private sector. ${ }^{84}$ Then, with the quantities approach, we can use the market for "price discovery," to ascertain the efficient way of achieving this goal, provided we have bankable caps. (Similar results hold if the government is less informed about the social damage function. This can be particularly important when there are lags in government policy.) Especially with bankable caps (in a system of quantity controls), an event today that is rationally anticipated to lead to more stringent controls and a higher market price for carbon in the future will affect markets and behavior before the government actually adjusts the level of caps (See Koch et al., 2017). By contrast, with a carbon tax, in the presence of information and adjustment asymmetries, the anticipation of a higher price of carbon in the future may result in more pollution today, exacerbating emissions volatility, in what may be viewed as intertemporal leakages. ${ }^{85}$ The efficiency losses of adjustment may thus be lower in a carbon market than with carbon taxes. ${ }^{86}$ Under these assumptions, there is some presumption for using an auctionedquantity approach with bankable caps. (An auction avoids the difficult problem of allocating emission rights, which in turn results in large political economy problems.)

\subsection{Towards a More General Framework and Finding the Basis of a Political Consensus in the} Presence of Differences in Beliefs

\footnotetext{
${ }^{84}$ Framing the question this way biases the result: when what we care about is the quantity, it is perhaps no surprise that a quantity-regime is preferable. The Weitzman prices vs. quantities analysis centers around situations where we have to ascertain the optimal quantity. Still, the following discussion on the use of market mechanisms is relevant because it highlights the importance of information asymmetries: in the absence of such asymmetries, the government could have achieved the desirable quantity trajectory by setting a trajectory for carbon prices.

${ }^{85}$ Thus, it is possible that the private sector has better information not only about the abatement function but also about the damage function. Even if the private sector has no intrinsic interest in the environment, if it anticipates that information about the social damage function will eventually be learned by the government, leading to more stringent controls, it will undertake abatement actions, engaging in emissions smoothing better than if the government set prices based on its (poorer) information.

${ }^{86}$ See also Park, Hepburn, and Keohane (2013).
} 
There is, of course, no reason to restrict ourselves to the limiting cases of prices vs. quantities. One can introduce a non-linear price schedule, two limiting forms of which are the pure price system and the pure quantity system.

While the literature on optimal tax interventions has clearly explained the advantages of such more general systems (Roberts and Spence, 1976; Pizer, 2002), there are also general results suggesting that under a variety of special, but frequently assumed, conditions linear pricing would be optimal ${ }^{87}$.

The argument that there is a preference for simple systems is also unconvincing: there are simple piece wise systems. For instance, a quantity system where there is a maximum price and a price system in which there is a maximum quantity of emissions. Such a system obviously limits the amount of emissions, charging a very high price if it turns out that the costs of emission reductions is very high, so that with, say, a moderate price, the level of emissions reductions is not sufficient to meet what is thought to be the requisite level of emissions reductions ${ }^{88}$.

There is one aspect of these systems with safety values that has not received sufficient attention: In a world in which individuals have different expectations (beliefs), if appropriately structured, they can provide the basis of greater consensus. ${ }^{89}$ Consider a quantities-based restriction with a safety valve guaranteeing that the price will not exceed a critical level. Then environmentalists, who are confident that the quantities target can be met at reasonable cost, can support the safety valve, precisely because they think it is unlikely to have to be invoked. On the other hand, businesspeople, whose main concern with the quantities approach is that

\footnotetext{
${ }^{87}$ Indeed, under these restrictions, no differential commodity taxation is required at all, and a single carbon price would suffice to correct the climate externality. (Atkinson and Stiglitz, 1976; Kaplow 1996, 2006; Deaton 1979; Deaton and Stern 1986. These results are, of course, overturned with distributive concerns and restricted taxation (Stiglitz, 2018b.)

${ }^{88}$ See Narassimhan et al. (2018) for a description of similar emissions trading systems in California and in the Regional Greenhouse Gas Initiative (RGGI).

${ }^{89}$ Recent work has highlighted how the behavior of the economic system may differ markedly when individuals have different beliefs. Explicit and implicit bets among individuals may give rise to what Guzman and Stiglitz called pseudo-wealth-as they engage in bets, they both feel wealthier because they both believe on average they will win. See Guzman and Stiglitz (2016a, 2016b).
} 
there is a risk of a very high implicit tax, can support the measure because that "tail risk" has been eliminated.

\section{Concluding Comments}

The Stern-Stiglitz report seemingly differed from orthodox economic policy entailing a single carbon price, for all uses, at all dates, in all places, in all uses by arguing for a more nuanced policy where carbon prices were supplemented by regulations and other government interventions and might vary across time, location, and uses. In fact, our report falls squarely with the mainstream of modern public finance. It is the advocates of a simplistic reliance on carbon taxes who have failed to take on board the insights of modern economics, which recognize the limitations posed by uncertainty, imperfect information, imperfect appropriability of investments in innovation, and restrictions on the sets of instruments available to government. We have attempted to show how, in particular, concerns about distribution, innovation, and uncertainty could justify the policies advocated in Stern-Stiglitz report. To be sure, the application of this more nuanced policy is more complicated. It will require a greater understanding of the structure of the economy and of the distributive effects of policies than an approach that relies simply on carbon taxes. In particular, we have discussed countering arguments, for instance, some arguing for a gradual adjustment of carbon prices, others for a short transition to a high carbon price; some suggesting the political economy advantages of a carbon tax with proceeds redistributed as a lump sum payment, others suggesting the advantages of a tax-cum-regulatory regime. Like the Stern-Stiglitz Commission, we have not attempted to undertake an overall balancing of these contrasting forces: the overall assessment will almost surely differ across countries and over time. 


\section{References}

Acemoglu, D., “Directed Technical Change," The Review of Economic Studies, 69(4), October 2002, pp. 781-809.

2010, "When Does Labor Scarcity Encourage Innovation?" Journal of Political Economy, 118(6), December, pp. 1037-1078.

2015, "Localised and Biased Technologies: Atkinson and Stiglitz's New View, Induced Innovations, and Directed Technological Change, " The Economic Journal, 125(583), March, pp. 443-463.

Acemoglu, P. Aghion, L. Bursztyn and D. Hemous, "The Environment and Directed Technical Change," The American Economic Review, 102(1), February 2012, pp. 131-166.

Akerlof, G. A. and J. L. Yellen, (1985a), "A Near-rational Model of the Business Cycle, with Wage and Price Intertia," The Quarterly Journal of Economics, 100(5), pp. 823-838.

(1985b), "Can Small Deviations from Rationality Make Significant Differences to Economic Equilibria?" American Economic Review, 75(4), pp. 708-720.

Arnott, R. and J. E. Stiglitz, "Randomization with Asymmetric Information," Rand Journal of Economics, 19(3), Autumn 1988, pp. 344-362

Arrow, K. J., "The Economic Implications of Learning by Doing," The Review of Economic Studies, 29(3), June 1962, pp. 155-173.

Atkinson, A. B. and J. E. Stiglitz, "A New View of Technological Change," Economic Journal, 79(315), September 1969, pp. 573-578.

1972, "The Structure of Indirect Taxation and Economic Efficiency," Journal of Public Economics, 1(1), April, pp. 97-119.

1976, "The Design of Tax Structure: Direct Versus Indirect Taxation," Journal of Public Economics, 6(1-2) , July-August, pp. 55-75. 
1980, Lectures on Public Economics, New York and London : McGraw-Hill Book

Company. Reprinted in 2015, with a new introduction, Princeton: Princeton University Press

Baumol, W. J. and W. Oates, "The Use of Standards and Prices for the Protection of the Environment," Swedish Economic Journal, 73(1), March 1971, pp. 42-54.

Bowles, S., "Endogenous Preferences: The Cultural Consequences of Markets and other Economic Institutions," Journal of Economic Literature 36(1), March 1998, pp. 75-111. 2016, The Moral Economy: Why Good Incentives are No Substitute for Good Citizens, Yale University Press.

Bowles and S. Polania-Reyes, "Economic Incentives and Social Preferences: Substitutes or Complements?" Journal of Economic Literature, 50(2), June 2012, pp. 368-425.

Caney, S. and C. Hepburn, "Carbon Trading: Unethical, Unjust and Ineffective?" Royal Institute of Philosophy Supplements, 69, October 2011, pp. 201-234.

Dasgupta, P. and J. E. Stiglitz, "Differential Taxation, Public Goods, and Economic Efficiency," Review of Economic Studies, 38(2), April 1971, pp. 151-174. 1972, “On Optimal Taxation and Public Production," Review of Economic Studies, 39(1), January, pp. 87-103.

Deaton, A., "Optimally uniform commodity taxes," Economics Letters, 2(4), 1979, pp. 357-36.

Deaton and N. Stern, "Optimally Uniform Commodity Taxes, Taste Differences, and Lump-sum Grants," Economic Letters, 20(3), December 1986, pp. 263-266.

Diamond, P. and J. A. Mirrlees, "Optimal Taxation and Public Production," American Economic Review, 61(1), March 1971, pp. 8-27, 261-278.

Dietz, S. and F. Venmans, "Cumulative Carbon Emissions and Economic Policy: In Search of General Principles," Grantham Research Institute on Climate Change and the Environment, Working Paper No. 283, March 2018.

Drandakis, E. M. and E. R. S. Phelps, "A Model of Induced Invention, Growth, and Distribution," Economic Journal, 76, December 1966, pp. 832-840. 
Fellner, W., "Two Propositions in the Theory of Induced Innovations," The Economic Journal, 71(282), June 1961, pp. 305-308.

Fischer, C. and R.G. Newell, "Environmental and technology policies for climate mitigation," Journal of Environmental Economics and Management 55 (2), 2008, pp. 142-162

Flues, F. and A. Thomas, "The distributional effects of energy taxes," OECD Taxation Working Papers, No. 23, OECD Publishing, Paris, 2015.

Geanakoplos, J. and H. Polemarcharkis, "Existence, Regularity, and Constrained Suboptimality of Competitive Allocations when the Asset Market Is Incomplete," in W. Heller, R. Starr, and D. Starrett (Eds.), Essays in Honor of Kenneth Arrow, Cambridge University Press, Cambridge, Volume 3, 1986, pp.65-95.

Gerlagh, R., S. Kverndokk and K. Rosendahl, “The optimal time path of clean energy R\&D policy when patents have finite lifetime," Journal of Environmental Economics and Management, 67(1), January 2014, pp. 2-19.

Gintis, H., "Welfare Criteria With Endogenous Preferences: the Economics of Education," International Economic Review, 15(2), June, 1974.

Gneezy, U. and A. Rustichini, "Pay Enough or Don't Pay at All," The Quarterly Journal of Economics, 115(3), August 2000, pp. 791-810.

Gneezy, S. Meier and P. Rey-Biel, "When and Why Incentives (Don't) Work to Modify Behavior," Journal of Economic Perspectives, 25(4), Fall 2011, pp. 191-210.

Golosov, M. and R.E. Lucas Jr., "Menu Costs and Phillips Curves," Journal of Political Economy, 115(2), April 2007, pp. 171-199.

Goulder, L. H., M. A. C. Hafstead and R. C. Williams, III, “General Equilibrium Impacts of a Federal Clean Energy Standard," American Economic Journal: Economic Policy, 8(2), May 2016, pp. 186-218.

Grainger, C.A. and C. D. Kolstad, "Who Pays a Price on Carbon?" Environmental and Resource Economics 46(3), July 2010, pp. 359-376. 
Greenwald, B. and J. E. Stiglitz, "Externalities in Economies with Imperfect Information and Incomplete Markets," Quarterly Journal of Economics, 101(2), May 1986, pp. 229-264. “Toward a Theory of Rigidities," American Economic Review, 79(2), May 1989, pp. 36469.

Guzman, M. and J. E. Stiglitz, "A Theory of Pseudo-Wealth," Contemporary Issues in Macroeconomics: Lessons from The Crisis and Beyond, J. E. Stiglitz and M. Guzman (Eds.), IEA Conference Volume, No.155-II, Palgrave Macmillan, Houndmills, UK and New York, 2016.

2016, "Psuedo-Wealth and Consumption Fluctuations," NBER Working Paper No. 22838, November, and presented at the American Economic Association Meetings, January, 2015.

Habakkuk, H.J., American and British Technology in the Nineteenth Century, Cambridge University Press, Cambridge, 1962.

Helm, D., C. Hepburn and R. Mash, "Credible Carbon Policy," Oxford Review of Economic Policy, 19(3), Autumn 2003, pp. 438-450.

Hepburn, C., "Regulation by Prices, Quantities, or Both: A Review of Instrument Choice," Oxford Review of Economic Policy, 22(2), July 2006, pp. 226-247.

Hoel, M. and L. Karp, "Taxes and Quotas for a Stock Pollutant with Multiplicative Uncertainty," Journal of Public Economics, 82(1), October 2001, pp. 91-114. 2002, "Taxes Versus Quotas for a Stock Pollutant," Resource and Energy Economics 24(4), November, pp. 367-384.

Hoff, K. and J. E. Stiglitz, "After the Big Bang? Obstacles to the Emergence of the Rule of Law in Post-Communist Societies," American Economic Review, 94(3), June 2004, pp. 753 - 763. 2008, “Exiting a Lawless State," Economic Journal, 118(531), August, pp. 1474-1497. 2016, "Striving for Balance in Economics: Towards a Theory of the Social Determination of Behavior," Journal of Economic Behavior and Organization, 126, June, pp. 25-57. 
Holland, S. P., J.E. Hughes and C.R. Knittel, "Greenhouse Gas Reductions Under Low Carbon Fuel Standards?" American Economic Journal: Economic Policy, 1(1), February 2009, pp. 10646.

IPCC, 2013: Climate Change 2013: The Physical Science Basis. Contribution of Working Group I to the Fifth Assessment Report of the Intergovernmental Panel on Climate Change (Stocker, T.F., D. Qin, G.-K. Plattner, M. Tignor, S.K. Allen, J. Boschung, A. Nauels, Y. Xia, V. Bex and P.M. Midgley [eds.]), Cambridge University Press, Cambridge U.K. and New York.

Jeanne, O. and A. Korinek, "Excessive Volatility in Capital Flows: A Pigouvian Taxation Approach," American Economic Review, 100(2), May 2010, pp. 403-07.

Kahneman, D., P. P. Wakker and R. Sarin, "Back to Bentham? Explorations of Experienced Utility," The Quarterly Journal of Economics, 112(2), May 1997, pp. 375-406.

Kalkuhl, M., O. Edenhofer and K. Lessmann, “Learning or Lock-in: Optimal Technology Policies to Support Mitigation," Resource and Energy Economics, 34(1), January 2012, pp. 1-23.

Karp, L., and C. Traeger, "Prices versus Quantities Reassessed," CESifo Working Paper Series 7331, November, 2018.

Karplus, V. J., S. Paltsev, M. Babiker and J. M. Reilly, "Should a vehicle fuel economy standard be combined with an economy-wide greenhouse gas emissions constraint? Implications for energy and climate policy in the United States," Energy Economics, 36, March 2013, pp. 322-333.

Kaplow, L., "The Optimal Supply of Public Goods and the Distortionary Cost of Taxation," National Tax Journal, 49(4), December 1996, pp. 513-33. 2006, “Optimal Control of Externalities in the Presence of Income Taxation," NBER Working Paper 12339, June.

Kennedy, C., "Induced Bias in Innovation and the Theory of Distribution," The Economic Journal, 74(295), September 1964, pp. 541-547. 
Klenert, D., L. Mattauch, E. Combet, O. Edenhofer, C. Hepburn, R. Rafaty and N. Stern, “Making Carbon Pricing Work for Citizens," Nature Climate Change, 8(8), August 2018, pp. 669677.

Klenert and L. Mattauch, "How to Make a Carbon Tax Reform Progressive: The Role of Subsistence Consumption," Economics Letters, 138, January 2016, pp. 100-103.

Korinek, A. and J. E. Stiglitz, "Political Economy in a Contestable Democracy: The Case of Dividend Taxation," 2008 Meeting Papers, Society for Economic Dynamics. 2009, “Dividend Taxation and Intertemporal Tax Arbitrage," Journal of Public Economics, 93(1-2), February, pp. 142-159. 2019, “Artificial Intelligence, Worker-Replacing Technological Progress and Income Distribution," in Economics of Artificial Intelligence, NBER/University of Chicago Press, Chicago. Kverndokk, S. and K. E. Rosendahl, "Climate Policies and Learning by Doing: Impacts and Timing of Technology Subsidies," Resource and Energy Economics, 29(1), January 2007, pp 5882.

Lanz, B., J. D. Wurlod, L. Panzone and T. Swanson, "The Behavioral Effect of Pigovian Regulation: Evidence From a Field Experiment," Journal of Environmental Economics and Management, 87, January 2018, pp. 190-205.

Levinson, A., "Energy Efficiency Standards Are More Regressive Than Energy Taxes: Theory and Evidence," Journal of the Association of Environmental and Resource Economists, University of Chicago Press, 6(S1), 2019, pp. 7-36.

Lipsey, R. G. and K. Lancaster, "The General Theory of Second Best," The Review of Economic Studies, 24(1), January 1956, pp. 11-32.

Mankiw, N. G., "Small Menu Costs and Large Business Cycles: A Macroeconomic Model of Monopoly," The Quarterly Journal of Economics, 100(2), May 1985, pp. 529-538.

Mattauch, L. and C. Hepburn, “Climate Policy When Preferences are Endogenous-and Sometimes They Are," INET Oxford Working Paper no. 2016-04, July 2016.

Mattauch, C. Hepburn and N. Stern, "Pigou Pushes Preferences: Decarbonisation Options When Preferences are Endogenous," CESifo Working Paper 7404, December 2018. 
Millar, R., M. Allen, J. Rogelj and P. Friedlingstein, "The Cumulative Carbon Budget and Its Implications," Oxford Review of Economic Policy, 32(2), April 2016, pp. 323-342.

Mirrlees, J. A., "An Exploration in the Theory of Optimal Income Taxation," Review of Economic Studies, 38(2), April 1971, pp. 175-208. 1975, “Optimal Commodity Taxation in a Two-Class Economy," Journal of Public Economics, 4(1), February, pp. 27-33.

Narassimhan, E., K. S. Gallagher, S. Koester and J. R. Alejo, "Carbon Pricing in Practice: A Review of Existing Emissions Trading Systems," Climate Policy, 18(8), April 2018, pp. 1-25.

Park, J., C. Hepburn and N. Keohane, “Does Benefit Uncertainty Matter for Climate Policy Design? A Case for Tradable Permit Markets with Banking," June 25, 2013.

Patrizio, P. S., F. Leduc, S. Kraxner, S. Fuss, G. Kindermann, S. Mesfun, K. Spokas, A. Mendoza, N. MacDowell, E. Wetterlund, J. Lundgren, E. Dotzauer, P. Yowargana and M. Obersteiner, “Reducing US Coal Emissions Can Boost Employment," Joule, 2, November 2018, pp. 116.

Pizer, W. A., "Combining Price and Quantity Controls to Mitigate Global Climate Change," Journal of Public Economics, 85(3), September 2002, pp. 409-434.

Roberts, M. J. and M. Spence. "Effluent Charges and Licenses Under Uncertainty," Journal of Public Economics, 5(3-4), May 1976, pp. 193-208.

Samuelson, P. A., "A Theory of Induced Innovation Along Kennedy-Weisäcker Lines," The Review of Economics and Statistics, 47(4), November 1965, pp. 343-356.

Sandmo, A., "Optimal Taxation in the Presence of Externalities," The Swedish Journal of Economics, 77(1), January 1975, pp. 86-98.

Sandel, M. J., What Money Can't Buy: The Moral Limits of Markets, Macmillan, New York, 2012.

Sinclair, P., "High Does Nothing and Rising Is Worse: Carbon Taxes Should Keep Declining to Cut Harmful Emissions," The Manchester School, 60(1), March 1992, pp. 41-52. 1994, "On the Optimum Trend of Fossil Fuel Taxation," Oxford Economic Papers, 46(1), 
October, pp. 869-877.

Sterner, T. (Ed.), Fuel Taxes and the Poor: The distributional consequences of gasoline taxation and their implications for climate policy, RFF Press, Routledge, Washington, D.C., 2012.

Stiglitz, J. E., "The Rate of Discount for Cost-Benefit Analysis and the Theory of the Second Best," Discounting for Time and Risk in Energy Policy, R. Lind (Ed.), Resources for the Future, 1982, pp. 151-204.

1986, Economics of the Public Sector, W.W. Norton ( $2^{\text {nd }}$ edition, $1988,3^{\text {rd }}$ edition, 2000), New York.

1987a, "Learning to Learn, Localized Learning and Technological Progress," Economic Policy and Technological Performance, P. Dasgupta and Stoneman (eds.), Cambridge University Press, London, pp. 125-153.

1987b, "Pareto Efficient and Optimal Taxation and the New New Welfare Economics," in Handbook on Public Economics, A. Auerbach and M. Feldstein (Eds.), Volume 2, NorthHolland, Amsterdam, pp. 991-1042.

1998a, "Pareto Efficient Taxation and Expenditure Policies, With Applications to the Taxation of Capital, Public Investment, and Externalities," presented at the Conference in Honor of Agnar Sandmo, Bergen, January. 1998b, "The Private Uses of Public Interests: Incentives and Institutions," Journal of Economic Perspectives, 12(2), Spring, pp. 3-22. (Originally presented as Society of Government Economists Distinguished Lecture on Economics in Government, ASSA meetings, January 4, 1998.) 2006, "Samuelson and the Factor Bias of Technological Change," Samuelsonian Economics and the Twenty-First Century, M. Szenberg et al. (Eds.), Oxford University Press, New York, pp. 235-251. 
2009, "Simple Formulae for Optimal Income Taxation and the Measurement of Inequality," in Arguments for a Better World: Essays in Honor of Amartya Sen, Volume I, Ethics, Welfare, and Measurement, K. Basu and R. Kanbur (Eds.), Oxford University Press, Oxford, pp. 535-566. (Revision of IMSSS Technical Report No. 215, Stanford University, August 1976).

2013, "Sharing the Burden of Saving the Planet: Global Social Justice for Sustainable Development," M. Kaldor and J. E. Stiglitz, (Eds.), The Quest for Security: Protection without Protectionism and the Challenge of Global Governance, Columbia University Press, New York, pp. 161-190.

2014, “Unemployment and Innovation," NBER Working Paper 20670, November. 2017, "Overcoming the Copenhagen Failure with Flexible Commitments," Global Carbon Pricing: The Path to Climate Cooperation, P.Cramton, D. J. C. Mackay, A. Ockenfels, and S. Stoft (Eds.), MIT Press, Cambridge, Mass., 2017, pp. 99-108; also in Economics of Energy and Environmental Policy, 4(2), Symposium on International Climate Negotiations, September 2015, pp. 29-36.

2018a, "Unemployment, Welfare, and Innovation," paper presented to ASSA meetings, Philadelphia, PA, January.

2018b, "Pareto Efficient Taxation and Expenditures: Pre- and Re-distribution," Journal of Public Economics Special Issue in Honor of Sir Tony Atkinson (1944-2017), E. Luttmer and H. Kleven (Eds.), 162, June, pp. 101-119.

2018c, "Expert Report in Juliana et al vs the United States of America," filed June 28.

Stiglitz and B. Greenwald, "Creating a Learning Society: A New Approach to Growth, Development, and Social Progress," Columbia University Press, New York, 2014. 
Stiglitz, N. Stern and the members of the High-Level Commission on Carbon Prices, "Report of the High-Level Commission on Carbon Prices," Carbon Pricing Leadership Coalition, International Bank for Reconstruction and Development and International Development Association/The World Bank, May 29, 2017, accessible at https://www.carbonpricingleadership.org/report-of-the-highlevel-commission-oncarbon-prices/.

Tversky, A. and D. Kahneman, "Loss Aversion in Riskless Choice: A Reference-Dependent Model," The Quarterly Journal of Economics, 106(4), November 1991, pp. 1039-1061.

Tvinnereim, E. and M. Mehling, "Carbon pricing and deep decarbonisation," Energy Policy, 121, October 2018, pp. 185-189.

Ulph, A. and D. Ulph, "The Optimal Time Path of a Carbon Tax," Oxford Economic Papers, 46(1), October 1994, pp. 857-868.

Van der Ploeg, F., "The Safe Carbon Budget," Climatic Change, 147(1-2), March 2018, pp. 47-59.

Wei, M., S. Patadia and D. M. Kammen, "Putting Renewables and Energy Efficiency to Work: How Many Jobs Can the Clean Energy Industry Generate in the US?" Energy Policy, 38(2), February 2010, pp. 919-931.

M. L. Weitzman, “Prices vs. Quantities,” Review of Economic Studies, 41(4), October 1974, pp. 477-491.

1977, "Is the Price System or Rationing More Effective in Getting a Commodity to Those Who Need it Most?" Bell Journal of Economics, 8(2), Autumn, pp. 517-524 